Reference: Merryweather G, Spearpoint M J. Flame spread measurements on wood products using the ASTM E 1321 LIFT apparatus and a reduced scale adaptation of the cone calorimeter. Fire and Materials, 34 (3), p.109136, 2010, http://dx.doi.org/10.1002/fam.1001.

\title{
Flame spread measurements on wood products using the ASTM E 1321 LIFT apparatus and a reduced
} scale adaptation of the cone calorimeter

\author{
G. Merryweather ${ }^{a}$, M.J. Spearpoint ${ }^{b, *}$ \\ ${ }^{a}$ Lincolne Scott Ltd, Auckland, New Zealand. \\ ${ }^{b}$ Department of Civil and Natural Resources Engineering, University of Canterbury, New Zealand.
}

\begin{abstract}
Flame spread experiments were conducted in an ASTM E 1321 Lateral ignition and Flame Transport (LIFT) apparatus and a Reduced scale Ignition and Flame spread Test (RIFT) adaptation of the cone calorimeter. Wood based products were tested and a flame spread model was applied to the results to obtain the flame spread parameter and the minimum heat flux required for flame spread. The materials used were plywood, medium density fibreboard, hardboard, two particle board products, Melamine (Melteca) covered products with two types of wood substrate along with New Zealand grown Rimu, Beech, Macrocarpa and Radiata Pine. The RIFT gave comparable results to the LIFT for several of the materials investigated. There appeared to be an effective limit on suitable materials that can be successfully tested in the RIFT to those that have a minimum flux for flame spread of less than $7 \mathrm{~kW} / \mathrm{m}^{2}$. This limitation was due to the rapid decay of the heat flux profile along the sample and the lower resolution dictated by the smaller size of the RIFT apparatus. It was found that the limit on the minimum heat flux for flame spread was approximately equivalent to a minimum ignition flux of $18 \mathrm{~kW} / \mathrm{m}^{2}$.
\end{abstract}

Keywords: Flame spread, LIFT apparatus, RIFT apparatus, cone calorimeter, wood products.

* corresponding author, michael.spearpoint@canterbury.ac.nz, tel: +64 3364 2237, fax: +64 33642758. 


\section{Nomenclature}

Symbol
$b$
$c$
$C$
$D$
$h$
$k$
$k \rho c$
$\dot{q}^{\prime \prime}$
$t$
$t^{*}$
$T$
$V$
$\delta_{f}$
$\varepsilon$
$\Phi$
$\rho$
$\sigma$

Name

Ignition parameter

Specific heat

Flame spread modulus

Thermal penetration depth

Heat transfer coefficient

Thermal conductivity

Thermal inertia

Heat flux

Time

Time for thermal equilibrium

Temperature

Velocity

Length heated in front of flame

Emissivity

Flame spread parameter

Density

Stefan- Boltzmann constant
Units

$\mathrm{S}^{-1 / 2}$

$\mathrm{J} / \mathrm{kg} . \mathrm{K}$

$\mathrm{m}^{3 / 2} / \mathrm{kW} . \mathrm{s}^{1 / 2}$

$\mathrm{m}$

$\mathrm{kW} / \mathrm{m}^{2} \cdot \mathrm{K}$

$\mathrm{kW} / \mathrm{m} . \mathrm{K}$

$\left(\mathrm{kW} / \mathrm{m}^{2} \cdot \mathrm{K}\right)^{2} \mathrm{~s}$

$\mathrm{kW} / \mathrm{m}^{2}$

S

S

${ }^{\circ} \mathrm{C}$

$\mathrm{m} / \mathrm{s}$

$\mathrm{m}$

$\mathrm{kW}^{2} / \mathrm{m}^{3}$

$\mathrm{kg} / \mathrm{m}^{3}$

$5.67 \times 10^{-8} \mathrm{~kW} / \mathrm{m}^{2} . \mathrm{K}^{4}$

\section{Subscripts}

crit

c

e

f

ig

$\min$

S

surf

$\mathrm{t}$

$\mathrm{x} \mathrm{mm}$

$\infty$
Critical ignition value

Convective

Incident on surface

Flame

At ignition

Minimum value

Required for flame spread

Surface

At $t$ seconds

Measured at the $\mathrm{x}$ mm position on the sample

Ambient 
The underlying basis for many predictions of flashover and room fire growth rely on the study of flame spread along the surface of materials [1]. Flame spread is divided according to the direction of any forced or buoyancy driven flow in regard to the direction of flame travel. In the case of wind assisted or vertical flame spread, the flame extends over the unburnt area, increasing the area affected by the radiation from the flame and hence the pre-heating of the material whereas lateral (or opposed flow) flame spread does not involve flame extension over the unpyrolised area.

The Lateral Ignition and Flame Transport (LIFT) apparatus, which forms the basis of the lateral flame spread measurements in the ASTM E 1321-97a standard [2] is bulky with a footprint of approximately $1.7 \mathrm{~m}$ by $0.9 \mathrm{~m}$ and requires a gas and compressed air supply for a radiant gas panel. Babrauskas [3] put the number LIFT testing facilities in the world at 20. In comparison, the ASTM E 1354 cone calorimeter [4] is an extensively used test apparatus and by 1995 nearly 100 were in worldwide service. However in its usual application the cone calorimeter cannot be used to directly measure flame spread and efforts to apply cone calorimeter data to modelling lateral flame spread have had limited success [5].

Research by Azhakesan et al. [6,7] at FireSERT at the University of Ulster developed the Reduced scale Ignition and Flame spread Test (RIFT) apparatus. This apparatus uses the cone calorimeter as the heat source for flame spread testing in a similar manner as the LIFT. Application of the flame spread procedures and theory developed by Quintiere et al. $[8,9,10]$ gives the flame spread parameter $(\Phi)$ not otherwise obtainable from cone calorimeter data. Previous work using the RIFT $[6,7]$ have compared results with data published in the literature but not directly against LIFT tests using the same batch of material. This paper compares results from the RIFT with the same materials tested in the LIFT using a range of natural and manufactured wood products available in New Zealand and more details are available in Merryweather [11].

\section{FLAME SPREAD THEORY}

\subsection{Ignition}

Flame spread is often regarded as a series of piloted ignitions and thus depends on the ignition properties of the material. The pyrolysis area adjacent to the flame front is heated by the flame as well as from the incident heat flux from any external heat source, leading to a process of progressive ignition. There are a number of models for predicting ignition under given flux conditions, which are discussed in depth by Babrauskas $[12,13]$. At the simplest level, a material will ignite when a sufficient quantity of material has pyrolised to reach the lower flammable limit, and in the case of a piloted ignition, a suitable ignition source is available. Using the pyrolysis of the material as an ignition criterion is often not practical and more desirable is a value for the incident heat flux or a temperature at which the item will not ignite, and hence the fire will no longer spread. 
The ignition theory developed by Quintiere, Harkleroad and Walton [9] and further developed by Quintiere and Harkleroad [10] forms the basis for the ignition procedure in the ASTM E 1321 LIFT ignition tests and the material properties used in the flame spread part of the test. The theory is based on an energy balance into a control volume for a thermally thick one-dimensional slab where the sample is assumed to be 'well behaved' with homogeneous properties, unaffected by the temperature increase to ignition, and the surface does not melt or blister. Analysis of the ignition tests provides the ignition parameter ' $b$ ' given as $b=\frac{2 h}{\sqrt{\pi k \rho c}}$ or $k \rho c=\frac{4}{\pi}\left(\frac{h}{b}\right)^{2}$ which can be used to derive the effective thermal inertia $k \rho c$ where $h$ is a linearised heat transfer coefficient.

The moisture content of the materials, particularly wood, can have an effect on the time to ignition and hence the flame spread rate. Dietenberger [14] conducted experiments with the LIFT and cone calorimeter on redwood, with oven dried ( $0 \% \mathrm{MC}), 30 \%$ and $50 \% \mathrm{MC}$ however Babrauskas [13] notes that changes in moisture content of timber at room equilibrium do not make a significant difference to ignition time and that differences in ignition times for timber moisture contents between $0-12 \% \mathrm{MC}$ are lost in the data scatter.

\subsection{Opposed flow (lateral) flame spread}

As illustrated in Figure 1, for thermally thick materials, the flame spread velocity $V_{f}$ at any point along the sample involves an energy balance into a control volume ahead of the flame front [8] to determine the material properties [9]. A key assumption is that the length of the control volume is small and this is valid for opposed flow flame spread as the pre-heated area is limited by heat transfer from the flame. Quintiere [8] suggests the length of the control volume is up to $2 \mathrm{~mm}$ and the assumption is that the incident flux $\dot{q}_{e}^{\prime \prime}$ on the sample is constant over that length.

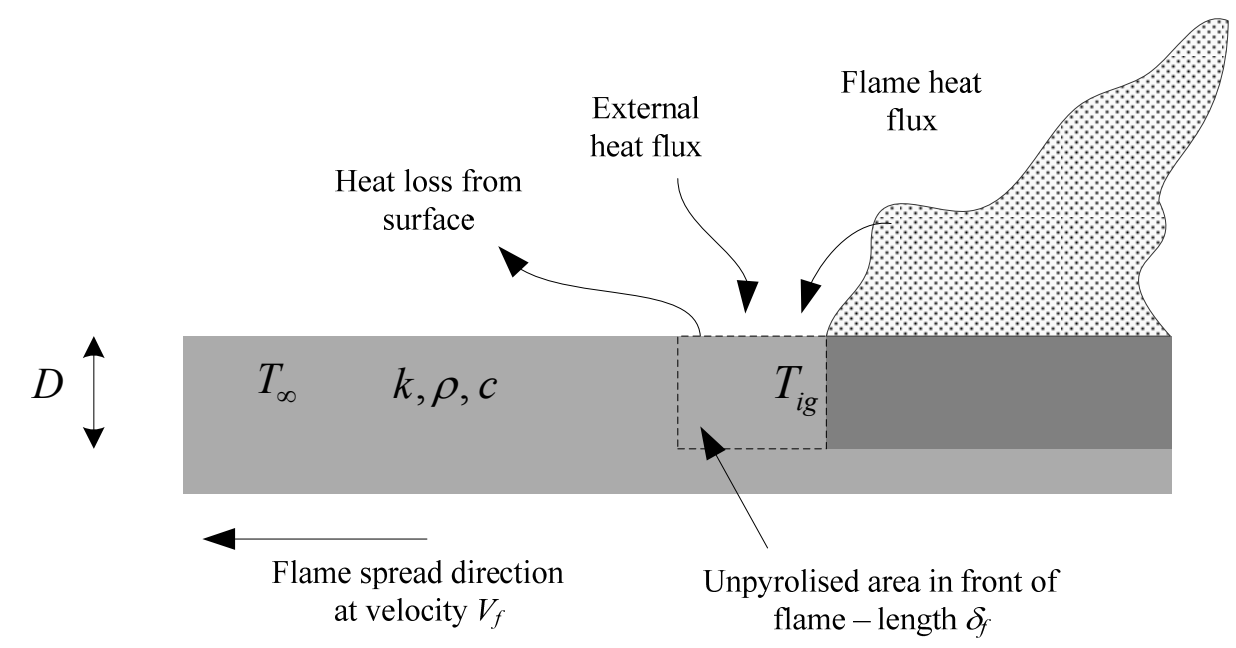

Figure 1: Opposed flow flame spread.

It is assumed that the control volume is pre-heated by the radiation from the flame of already-burning material, any external heat flux and conduction through the material. The material is assumed to ignite once the surface 
temperature reaches the minimum temperature for piloted ignition $\left(T_{i g}\right)$, and this temperature increase is due to the increase from the external flux and the flame heat flux:

$$
T_{i g}-T_{\infty}=\Delta T_{e}+\Delta T_{f}
$$

The depth of the control volume into the material $(D)$ is equal to the thermal penetration, which is material dependent, and is given as $D=\sqrt{k t / \rho c}$ for an exposure of $t$ seconds. The depth is 'thin' over the time it takes to heat the length of the control volume from ambient temperature to the ignition temperature. If the surface material is at equilibrium with the external heat flux $\dot{q}_{e}^{\prime \prime}$ due to a pre-heating period, then an energy balance on the control volume $D . \delta_{f}$ in size, moving at the flame front velocity $V_{f}$ is

$$
\rho c D V_{f}\left(T_{i g}-T_{\infty}\right) \cong \dot{q}_{f}^{\prime \prime} \delta_{f} .
$$

The critical heat flux to raise the temperature of the surface to the ignition temperature in an 'infinite' time is given by

$$
\dot{q}_{e, c r i t}^{\prime \prime}=h_{c}\left(T_{i g}-T_{\infty}\right)+\varepsilon \sigma\left(T_{i g}^{4}-T_{\infty}^{4}\right) \cong h\left(T_{i g}-T_{\infty}\right)
$$

and the emissivity is taken to be unity as the surface chars before ignition. The ignition temperature $\left(T_{i g}\right)$ is obtained from Figure 10 in Annex 1 of the ASTM E 1321-97a and hence $h$ can then be determined. Treating the control volume as a semi-infinite, thermally thick solid with one dimensional heat flow into the solid gives Equation (4) for the surface temperature up until ignition

$$
\Delta T_{e}=T_{\text {surf }}-T_{\infty}=\dot{q}_{e, x_{f}}^{\prime \prime}[1-\exp (a t) \operatorname{erfc} \sqrt{a t}] / h
$$

where $a=h^{2} / k \rho c$ and the surface ignites once it reaches the minimum surface temperature for ignition so that $T_{\text {surf }}=T_{i g}$. The inverse square root of the flame front velocity is found to be proportional to the difference between the critical ignition flux and the incident flux at that point. Combining Equation (2), Equation (4) and Equation (1) gives

$$
T_{i g}-T_{\infty}=\left[\frac{\dot{q}_{f}^{\prime \prime} \sqrt{\delta_{f}}}{\sqrt{k \rho c}}\right] V_{f}^{-1 / 2}+\dot{q}_{e, x_{f}}^{\prime \prime}[1-\exp (a t) \operatorname{erfc} \sqrt{(a t)}] / h
$$

or the flame front velocity is given as

$$
V_{f}^{-1 / 2}=C\left[h\left(T_{i g}-T_{\infty}\right)-\dot{q}_{e, x_{f}}^{\prime \prime} \cdot F(t)\right]
$$

where $C=1 / \dot{q}_{f}^{\prime \prime} \sqrt{a \delta_{f}}$ which is a material specific constant referred to as the flame heat transfer modulus and $F(t)=1-\exp (a t) \operatorname{erfc} \sqrt{(a t)}$.

The solution to Equation (6) requires the accurate measurement of the pre-heating area in front of the flame front as it progresses along the sample which is difficult to determine in practice. However, as the time the sample is exposed to the external flux increases, then the time transient term $F(t)$ tends to zero as the material surface approaches equilibrium. The ignition parameter ' $b$ ' can be used to calculate the required pre-heating time $t^{*}$ to 
bring the material to thermal equilibrium such that $t^{*}=(1 / b)^{2}$. If the pyrolysis area is assumed to be constant for a given material due to the fact there is no flame impingement on the unpyrolysed area, and the other constants are included in a new value, then equation for flame spread velocity is

$$
V_{f}=\frac{\Phi}{k \rho c\left(T_{i g}-T_{\infty}\right)^{2}}
$$

where the flame spread parameter $\Phi$ can be derived from experimental results using

$$
\Phi=\frac{4 / \pi}{(C b)^{2}} \text {. }
$$

The heat loss from the area in front of the flame front which has not yet ignited leads to the requirement for a minimum heat flux impinging on the surface and resulting surface temperature for the flame to spread. Without the heat flux to raise the temperature of the material, either from the flame or from an external source, the surface temperature will not be high enough to reach the ignition temperature, and hence there is a limiting flux for the material to give the ignition temperature required for flame spread. If the external heat flux is known and is specified as decaying along the sample then the minimum heat flux required for the flame to spread $\left(\dot{q}_{s}^{\prime \prime}\right)$ is given by the location of the flame front when it self-extinguishes. The minimum temperature for flame spread can be calculated by solving

$$
\dot{q}_{s}^{\prime \prime}=h_{c}\left(T_{s}-T_{\infty}\right)+\varepsilon \sigma\left(T_{s}^{4}-T_{\infty}^{4}\right) \cong h\left(T_{s}-T_{\infty}\right) .
$$

\section{LATERAL IGNITION AND FLAME TRANSPORT APPARATUS}

\subsection{LIFT apparatus design}

The ASTM E 1321 standards series originated from the ASTM E 1317 standard for marine surface finishes [15] and work by Quintiere et al. $[8,9,10]$. It uses the same test apparatus with the addition of a mathematical model of flame spread developed by Quintiere. The difference between the two standards is principally with the pilot flame location and the addition of a $180 \mathrm{~mm}$ long flange behind the pilot flame at the top of the sample holder. The ASTM E 1317 standard also uses a thermopile in the hood to give basic heat release data, and this is not used in the ASTM E 1321-97a test.

The LIFT test includes a procedure to obtain ignition properties of a material and a subsequent procedure to obtain opposed flame spread properties incorporating the ignition results. The LIFT test gives properties in the form of: thermal inertia $k \rho c$; minimum heat flux for ignition $\dot{q}_{i g, m i n}^{\prime \prime}$ and the resulting minimum surface temperature for ignition, $T_{i g}$; minimum heat flux for flame spread $\dot{q}_{s}^{\prime \prime}$ and the resulting minimum surface temperature for flame spread, $T_{s}$ and the flame spread parameter $\Phi$. 
The standard LIFT apparatus uses a gas fuelled diffusion burner and a $155 \mathrm{~mm}$ high by $800 \mathrm{~mm}$ long vertically oriented sample holder angled at $15 \pm 0.25^{\circ}$ to the face of the burner (Figure 2). The hot end of the sample is $125 \mathrm{~mm}$ away from the face of the burner, and offset from the edge of the burner by approximately $125 \mathrm{~mm}$. The burner is a flat panel $280 \mathrm{~mm}$ high by $430 \mathrm{~mm}$ long. The arrangement gives an almost constant flux level for the first $150 \mathrm{~mm}$ along the sample for use in ignition testing, and then a decreasing flux level to approximately $2 \%$ of the peak heat flux. The output of the burner can be varied to give desired flux levels by altering the air and gas settings. ASTM E 1321-97a calls for methane powered main burner with an air-acetylene pilot flame.

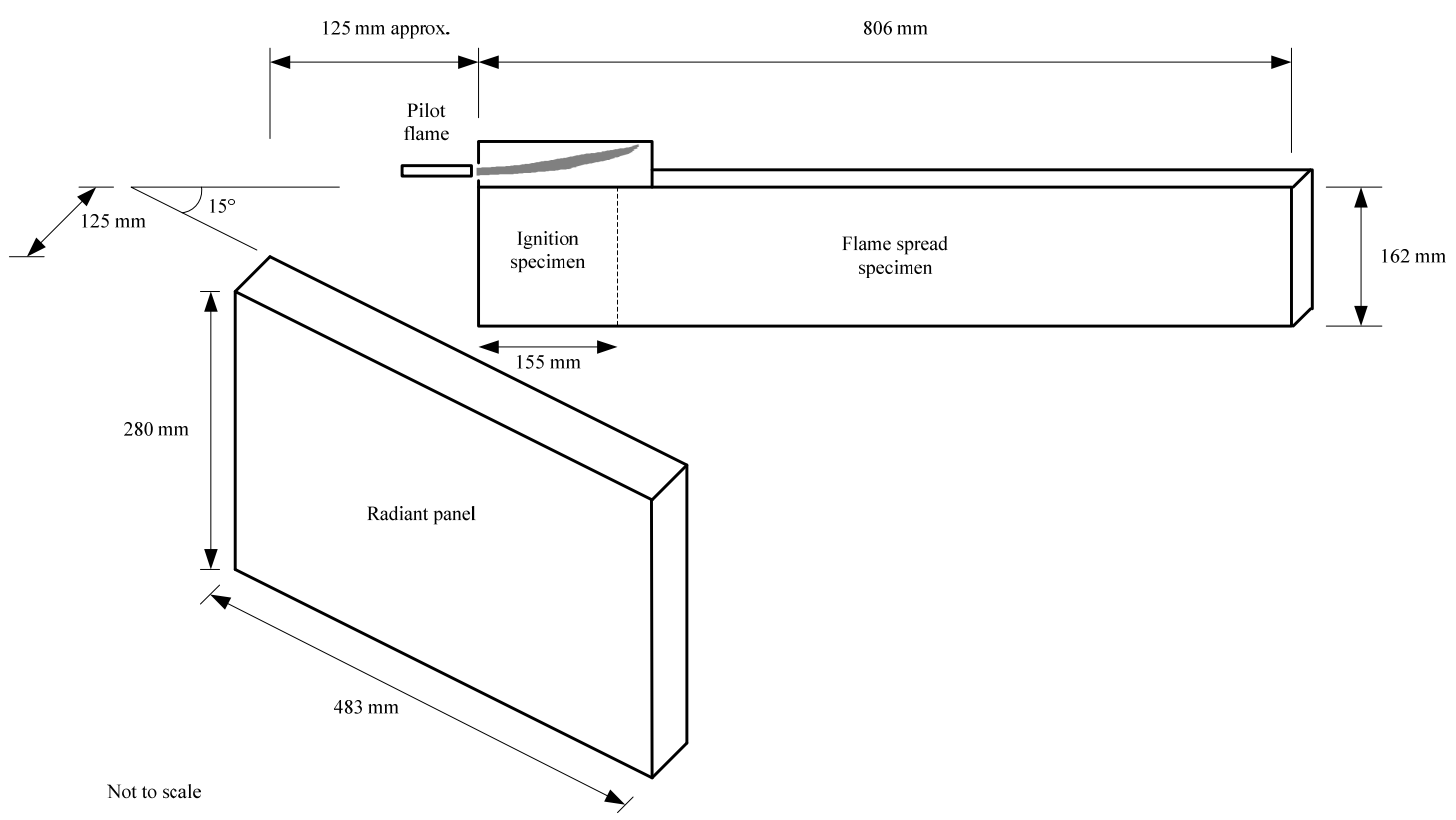

Figure 2: Main components of LIFT apparatus.

The thickness of the materials should be chosen appropriately. The ASTM E 1321-97a standard notes that materials in this category are typically $2-5 \mathrm{~mm}$ thick, and where the material is less than this, the results apply to the facing and substrate combination as the substrate can have a significant effect on the ignition and flame spread results.

\subsection{The University of Canterbury LIFT apparatus}

The LIFT apparatus used in this study followed ASTM E 1317 and the modifications listed for the ASTM E 1321-97a standard with some variations. Methane was used for the radiant panel in the original research [8] and the subsequent ASTM standard as it gives a wide range of incident heat fluxes for the ignition test procedure. However due to the unavailability of a suitable source of methane, the LIFT used in this study had a Liquefied Petroleum Gas (LPG) / compressed air supply for the main radiant panel burner fuel and the pilot flame. LPG is a mixture of propane and butane, and propane has been used for ignition experiments [16] with the ASTM E 1623 ICAL intermediate scale calorimeter [17], which also normally runs on methane or natural gas. Similarly, in a round robin test of ASTM E 1317 it was noted that one of the laboratories used propane for the radiant panel burner although this was later changed to methane [18]. 
It was found that the radiant panel burner had a lower limit of approximately $20-25 \mathrm{~kW} / \mathrm{m}^{2}$ at the $50 \mathrm{~mm}$ measuring point $\left(\dot{q}_{50 \mathrm{~mm}}^{\prime \prime}\right)$ when set up in accordance to the standard LIFT apparatus spacing as the burner behaviour became unstable and had uneven heating below this level. For wood based products the minimum ignition flux is in the order of $12-18 \mathrm{~kW} / \mathrm{m}^{2}[13,19]$ but usually higher for ignition tests conducted in the LIFT [12]. To achieve the required heat fluxes for the ignition tests the LIFT apparatus used in this study had its radiant panel mounted on rails to allow the spacing between the burner and sample to be adjusted. Incident fluxes of $11 \mathrm{~kW} / \mathrm{m}^{2}$ could be obtained for ignition testing while maintaining a stable burner flame. The lower heat flux limit was not generally a constraint for the flame spread tests as the flame spread procedure in ASTM E 1321-97a calls for a peak heat flux $5-10 \mathrm{~kW} / \mathrm{m}^{2}$ over the minimum ignition flux $\left(\dot{q}_{i g, \text { min }}^{\prime \prime}\right)$ from the ignition tests. The heat flux level that the panel is set at is not critical as it is only to increase the resolution by reducing the step size between each measuring point and to reduce changes to the material during the pre-heating period.

An upper limit of $\dot{q}_{50 \mathrm{~mm}}^{\prime \prime}=50 \mathrm{~kW} / \mathrm{m}^{2}$ was obtained as it was found that the air compressor was unable to supply sufficient air for the burner at higher outputs. In trials using an additional air compressor in parallel with the main air supply, the burner was capable of producing heat fluxes greater than $\dot{q}_{50 \mathrm{~mm}}^{\prime \prime}=60 \mathrm{~kW} / \mathrm{m}^{2}$, but there was not sufficient air capacity to hold this level for extended periods.

ASTM E 1321 provides a calibration curve for a heat flux profile when an apparatus is set to the standard angle and the burner output is set to $50 \mathrm{~kW} / \mathrm{m}^{2}$ at the $50 \mathrm{~mm}$ measuring position. The standard requites that an apparatus give heat fluxes to within $10 \%$ of the calibration curve at $50 \mathrm{~mm}$ intervals along a sample template. The average of three calibration runs is shown in Figure 3. From $600 \mathrm{~mm}$ onwards, the calibration results are outside the $10 \%$ limit, however this was found to be beyond the limit of flame spread along the sample for the materials tested, so was not considered to be important. Pauner [18] showed a similar level of variation at the cool end of the sample at the reference $\dot{q}_{50 \mathrm{~mm}}^{\prime \prime}$ heat flux. Work by Nisted [20] and Babrauskas and Wetterlund [21] also had the same discrepancy and adopted a similar approach as applied here. 


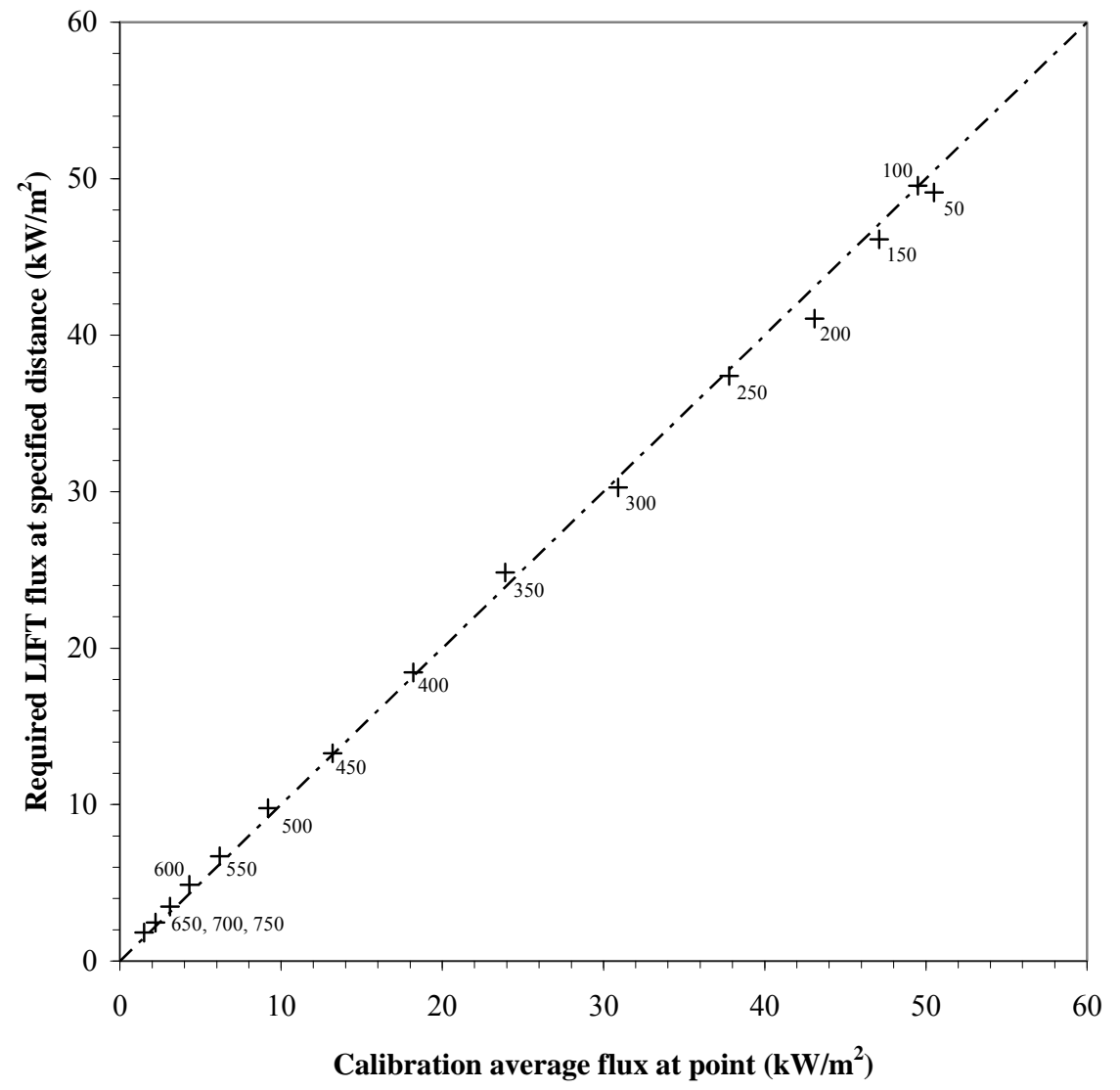

Figure 3: Comparison between LIFT calibration flux and ASTM E 1321 standard.

\subsection{Analysis of LIFT results}

Analysis of the LIFT tests yields the apparent ignition and flame spread properties for a given material. From the ignition tests the asymptote of a plot of time to ignition $\left(t_{i g}\right)$ versus heat flux $\left(\dot{q}_{e}^{\prime \prime}\right)$ provides the minimum ignition flux $\left(\dot{q}_{i g, \text { min }}^{\prime \prime}\right)$. The point at which the best-fit line of a plot of $\left(\dot{q}_{i g, \text { min }}^{\prime \prime}\right) /\left(\dot{q}_{e}^{\prime \prime}\right)$ versus $1 / \sqrt{ }\left(t_{i g}\right)=1$ gives the square root of the flame spread test pre-heating time $t^{*}$. The slope of the best fit line gives the ignition parameter ' $b$ ' and hence the thermal inertia, $k \rho c$. The choice of which data points to include can have a significant effect on the ignition parameter and particularly the pre-heating time $t^{*}$.

The flame spread test analysis uses the measurement of the heat flux at points along the sample face $\dot{q}_{e, x_{f}}^{\prime \prime}$ to allow the calculation of the flame spread velocity and minimum flux level for flame spread. The velocity of the flame front is calculated using a three point least squares fit calculated from the distance and time results. $F(t)$ is calculated for each interval along the sample, where $F(t)=1$ if the time from inserting the sample is greater than $t^{*}$. A graph of $1 / \sqrt{ } V_{f}$ on the y-axis against $\dot{q}_{e, x_{f}}^{\prime \prime} . F(t)$ on the x-axis is plotted and a regression line fitted to the data where its slope is the flame spread modulus $(C)$ and hence $\phi$ can be determined. The lowest value of 
$\dot{q}_{e, x_{f}}^{\prime \prime} \cdot F(t)$ gives the minimum heat flux for flame spread $\left(\dot{q}_{s}^{\prime \prime}\right)$ as an alternative to the measured heat flux at the point of the extent of flame spread on the sample during the test. The point at which the regression line crosses the x-axis gives an alternative means of calculating the minimum ignition flux $\dot{q}_{i g, \min }^{\prime \prime}$ obtained in the ignition test.

\section{REDUCED SCALE IGNITION AND FLAME TEST (RIFT)}

\subsection{RIFT design}

For conventional cone calorimeter testing the sample generally measures $100 \mathrm{~mm}$ by $100 \mathrm{~mm}$ and can be mounted horizontally or vertically. It is exposed to a heat flux of up to $100 \mathrm{~kW} / \mathrm{m}^{2}$ and information such as the time to ignition, mass loss rate, the heat release rate and toxic gas production are determined. There are a number of features that make the cone calorimeter different from other methods of bench scale fire testing. Most obviously is the use of the conical electric element rather than the gas-fired flat panel. The conical shape gives an almost constant heat flux across the face of the sample yet allows combustion products to escape without interfering with the radiation from the element. Rather than using a gas flame ignitor such as in the LIFT or ISO 5657 apparatus [12] the pilot ignition in the cone calorimeter is by a spark gap. The position of this is adjustable to be centred in the middle of a horizontal specimen, or at the top of a vertical specimen.

The RIFT is designed to provide an alternative to the LIFT test for opposed flow flame spread measurements using a modified cone calorimeter. While the RIFT as used in this study was only concerned with ignition and flame spread, Azhakesan et al. [7] used the RIFT data in conjunction with mass loss readings and calorimetry to give a simultaneous heat release rate as part of a room fire model.

Azhakesan et al. [6] obtained encouraging flame spread results however further independent work at the University of Newcastle by Pease [22] and by Huynh [23] was inconclusive. The principal problem in the later work was identified as the location of the sample, where the hot end of the sample was on the centreline of the cone, so only half the heat flux from the cone was available. The resulting flame spread was in the order of $90 \mathrm{~mm}$ along the sample [23] and the resolution was insufficient to give meaningful results. Furthermore Huynh's tests did not include the pre-heating time prior to flame spread testing as required in ASTM E 1321.

The procedure for using the RIFT apparatus is based on the ASTM E 1321 standard and follows the same methodology. The cone calorimeter element was set to the vertical position and the long axis centreline of the RIFT sample holder was inline with the centreline of the cone. The end of the sample closest to the element was in line with the edge of the element, as shown in Figure 4. The angle and sample separation distance was set by measuring perpendicularly from the face of the cone to the sample. The sample length used by Azhakesan was $100 \mathrm{~mm}$ by $350 \mathrm{~mm}$ whereas this work and the previous work by Huynh [23], Pease [22] used a sample size of $100 \mathrm{~mm}$ by $250 \mathrm{~mm}$. 


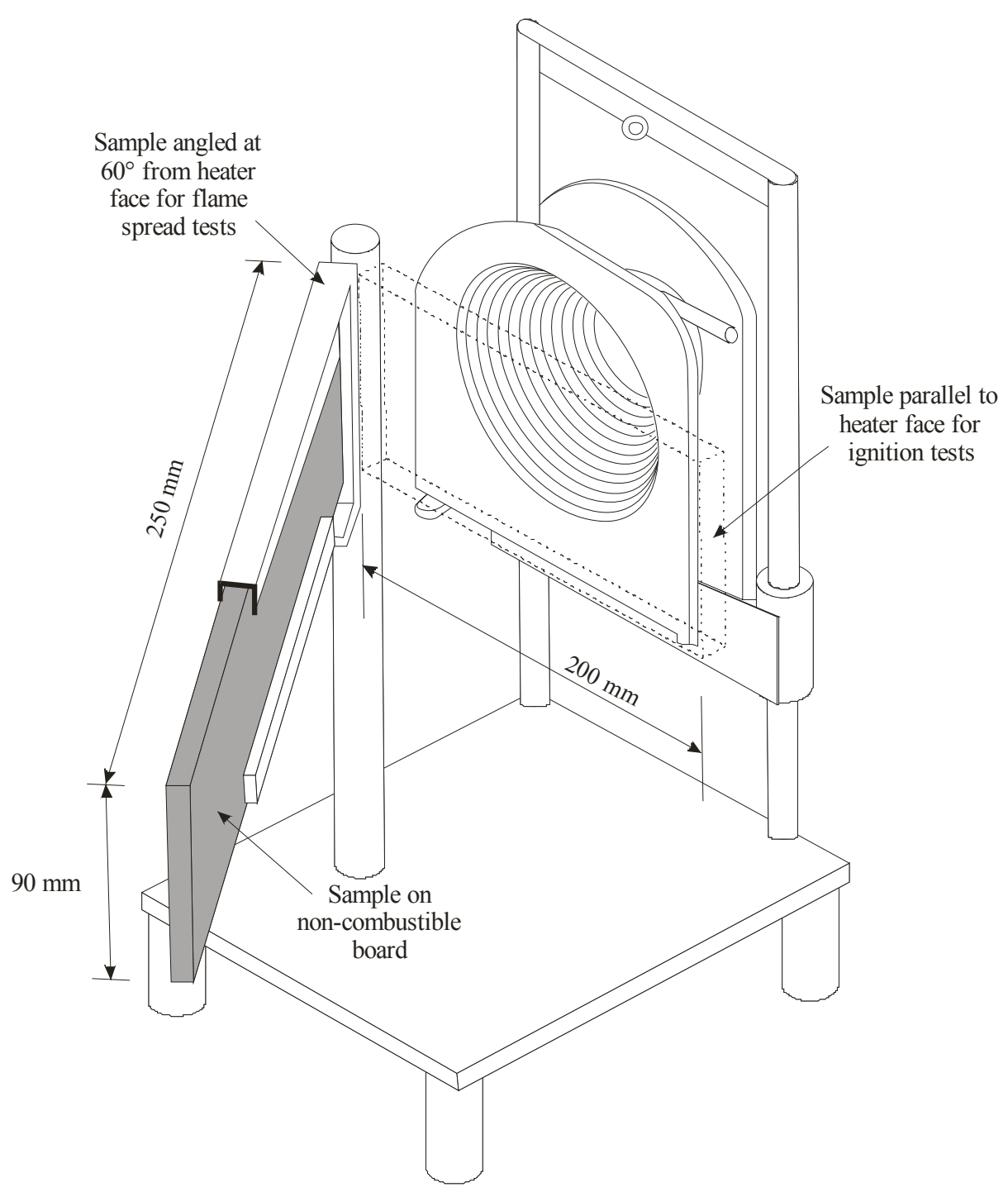

Figure 4: RIFT apparatus for ignition and flame spread testing - adapted from Azhakesan et al. [6].

\subsection{Heat flux characteristics}

The heat flux measurement along the sample was conducted using a template made from fibre cement board with location holes at $25 \mathrm{~mm}$ centres to take the head of a water cooled flux measuring gauge and this was inserted in into the sample holder. The element was running at the final temperature for at least 10 minutes before any readings are taken to allow the temperature of the element and apparatus to stabilise ensuring that the face of the heat flux gauge was flush with the face of the template and not inside the hole to ensure accurate readings of the incident flux at each point. The heat flux gauge was left in place for at least $30 \mathrm{~s}$ to allow an average reading of the heat flux over that time to be taken before moving to the next measuring point. As with the LIFT, having the head of the flux meter proud of the surface of the template at the cold end of the sample will improve the accuracy of the measurements due to the convection boundary layer. The effect of the smaller scale of the RIFT is shown in Figure 5 where the sample angle and peak heat flux is set at the same values for both sets of apparatus. The heat flux decays more rapidly in the RIFT as the measurement moves away from the element due to the directional nature and smaller size of the cone and consequently the smaller size of the sample. 


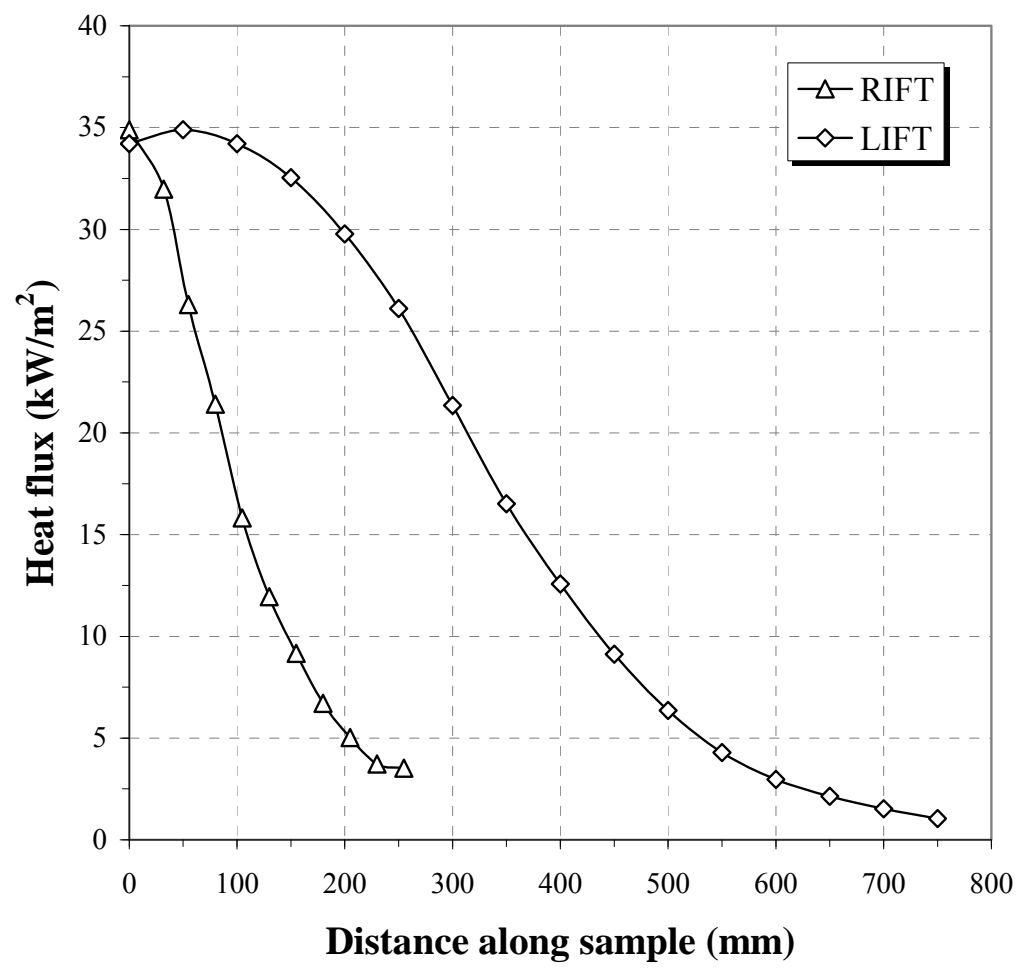

Figure 5: Heat flux for LIFT versus RIFT.

Azhakesan et al [6] used a peak heat flux of $35 \mathrm{~kW} / \mathrm{m}^{2}$ chosen to be typical of heat fluxes to walls in a fire. Pease [22] and Huynh [23] used a $60 \mathrm{~kW} / \mathrm{m}^{2}$, due to the different experimental setup. The peak heat flux for the RIFT is largely dictated by the available cone element temperature and increasing the peak heat flux level does little to increase the effective flame spread length. A nominal peak heat flux of $35 \mathrm{~kW} / \mathrm{m}^{2}$ at the hot end of the sample was used in this study similar to Azhakesan et al [6].

When the peak heat flux is kept constant by setting the cone temperature to suit, then the effect of changing the sample angle can be seen in Figure 6. The directional nature of the cone element can be seen by the location of the peak flux level along the sample, and the terminal heat flux, which remains relatively constant, despite the changing view factor. It was also noted that the directional nature of the cone element meant that increasing the distance between the sample and the element did not increase the spread of the irradiance along the sample within the limitations of the desired heat flux level. 


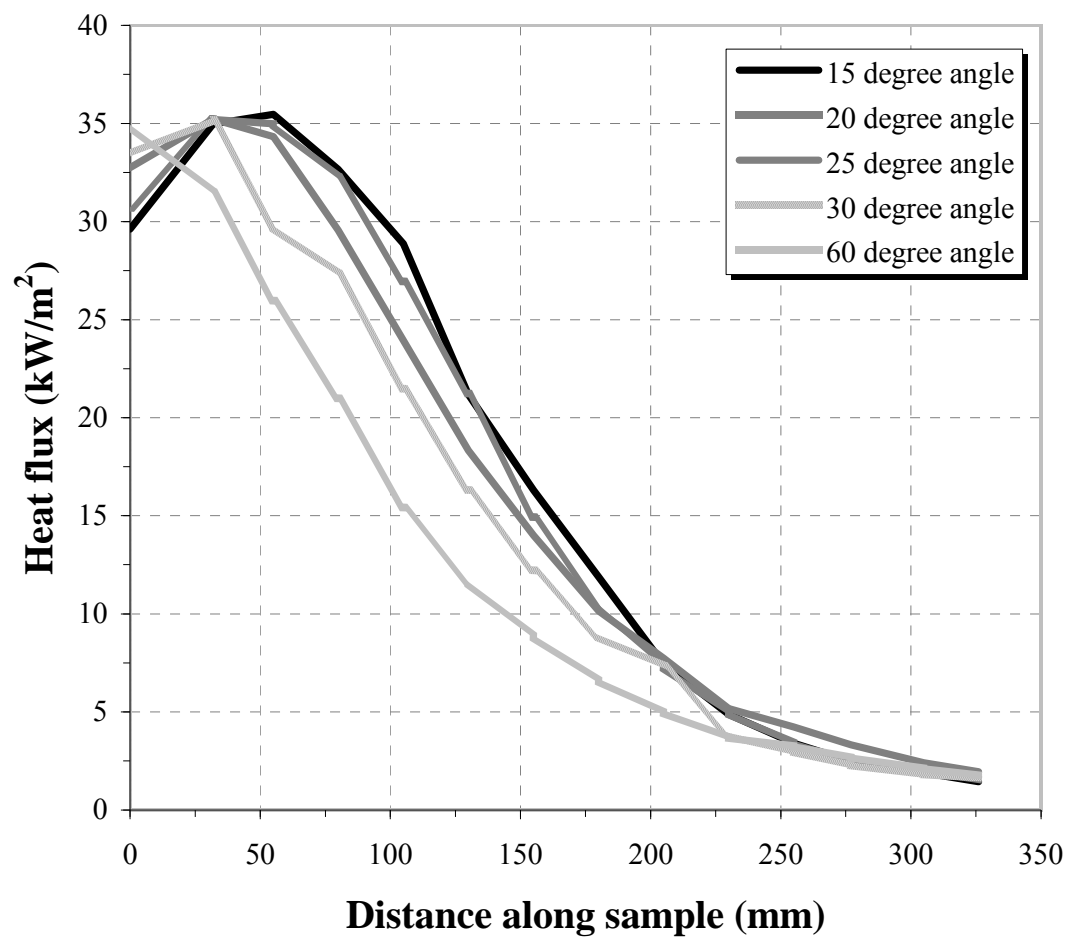

Figure 6: Irradiance along RIFT sample with constant peak heat flux of $35 \mathrm{~kW} / \mathrm{m}^{2}$ and $70 \mathrm{~mm}$ separation.

As the basis of flame spread measurements is to have a series of velocity versus received heat flux measurements, it follows that the distance along the sample from the point of the peak heat flux to the terminal heat flux where the flame spread stops should be as long as possible. The profile of the LIFT apparatus allows it to be used for ignition testing, as there is an almost flat heat flux curve for the first $150 \mathrm{~mm}$ of the sample. This feature is not required in the RIFT, as the cone calorimeter or ISO 5657 ignition apparatus can be used for ignition testing in the conventional manner. The maximum distance along the sample is when the peak heat flux coincides with the hot end of the sample, as the location of the terminal heat flux remains relatively unchanged. Hence the optimum angle chosen between the element face and the sample was found to be 60 degrees, similar to that determined previously $[6,22,23]$.

\section{EXPERIMENTAL PROGRAMME}

\subsection{Materials}

Nine wood based materials were used in the experimental programme (Table 1) with some limited tests conducted on variations of these materials. Most New Zealand manufactured wood products are Radiata Pine based as this is the most common species grown in New Zealand. The materials chosen were based on the availability of previously published data, particularly Huynh [23] and Azhakesan et al. [6] and to provide some information on New Zealand materials which was otherwise not available. 


\begin{tabular}{|c|c|c|c|c|c|}
\hline Material & $\begin{array}{l}\text { Manufacturer } \\
\text { and trade name }\end{array}$ & Description & $\begin{array}{c}\text { Thickness* } \\
\text { (mm) }\end{array}$ & $\begin{array}{l}\text { Density } \\
\left(\mathrm{kg} \cdot \mathrm{m}^{-3}\right)\end{array}$ & $\begin{array}{c}\text { Moisture } \\
\text { content } \\
(\%)\end{array}$ \\
\hline hardboard & unbranded & hardboard fibreboard & 5 & 819 & 6.3 \\
\hline plywood & IPL "Tuffply" & $\begin{array}{l}\mathrm{C} / \mathrm{D} \text { grade untreated } \\
\text { Radiata Pine }\end{array}$ & 17 & 487 & 7.8 \\
\hline $\begin{array}{l}\text { particle board } \\
\text { (chipboard) }\end{array}$ & $\begin{array}{l}\text { Laminex (FWP) } \\
\text { "Pynefloor" } \\
\text { Laminex (FWP) } \\
\text { "Superflake" }\end{array}$ & $\begin{array}{l}\text { Radiata Pine based } \\
\text { flooring particle board } \\
\text { Radiata Pine based } \\
\text { particle board. }\end{array}$ & 20 & 673 & 8.9 \\
\hline $\begin{array}{l}\text { medium density } \\
\text { fibreboard (MDF) }\end{array}$ & FWP “Customwood" & $\begin{array}{l}\text { Radiata Pine based } \\
\text { standard MDF }\end{array}$ & 18 & 620 & 7.1 \\
\hline $\begin{array}{l}\text { Melteca faced } \\
\text { MDF }\end{array}$ & $\begin{array}{l}\text { Laminex (FWP) } \\
\text { Melteca }\end{array}$ & $\begin{array}{l}\text { White Melamine faced } \\
\text { MDF }\end{array}$ & 18 & 681 & 8.2 \\
\hline $\begin{array}{l}\text { Melteca faced } \\
\text { particle board }\end{array}$ & $\begin{array}{l}\text { "Regal", from } \\
\text { builders merchant }\end{array}$ & $\begin{array}{l}\text { White Melamine pre - } \\
\text { finished shelving }\end{array}$ & 18 & 661 & $\mathrm{n} / \mathrm{a}$ \\
\hline Radiata Pine & - & $\begin{array}{l}\text { clear grade, kiln dried } \\
\text { and untreated }\end{array}$ & $16 / 20$ & 425 & 9.5 \\
\hline Macrocarpa & - & Clear grade & $16 / 20$ & 514 & 8.6 \\
\hline Rimu & - & $\begin{array}{l}\text { New Zealand, heart } \\
\text { grade }\end{array}$ & $16 / 20$ & 660 & 10.4 \\
\hline Beech & - & New Zealand & $16 / 22$ & 489 & 9.7 \\
\hline
\end{tabular}

* RIFT / LIFT

$\mathrm{n} / \mathrm{a}-$ not recorded

Table 1. Wood based materials tested.

Ignition tests for each material were conducted at different heat fluxes in the LIFT, the RIFT and the ISO 5657 apparatus, similar to the earlier work by Ngu [19], to obtain the material properties required for the flame spread tests and these results are presented elsewhere [24]. Ignition test data taken from the ISO 5657 apparatus were employed for the RIFT flame spread tests reported here.

A minimum of four samples of each material were tested for flame spread in the RIFT, with six samples if allowed by the available material. Three samples of each material were tested for flame spread in the LIFT. Some additional flame spread tests were conducted on different thickness materials of the same nominal type. As noted in Table 1, the thickness of the natural woods used in the RIFT was less than the samples used in the LIFT due to difficulties in inserting the thicker samples into the sample holder.

\subsection{Test procedures}

All materials used in the experiments were conditioned for at least two weeks at $23^{\circ} \mathrm{C} \pm 3^{\circ} \mathrm{C}$ and a relative humidity of $50 \% \pm 5 \%$ so that successive weighings taken 24 hours apart did not vary by more than $0.1 \%$ of the mass, as required by ASTM E1321-97a. The samples had the edges and back covered in aluminium foil during the test and an insulated backing board was used. 
Prior to the flame spread tests in the LIFT, the peak heat flux level was set to $5-10 \mathrm{~kW} / \mathrm{m}^{2}$ above the critical ignition flux obtained from the ignition tests and the heat flux profile along a sample template was recorded. The measuring template was removed, the sample holder containing the test specimen was slid into place and the timing started. As the heat flux level in the LIFT is effectively constant over the first $150 \mathrm{~mm}$ of the sample, the flame spread very rapidly over this section. If it was extensively charred from a long pre-heating period then it was difficult to ignite using the pilot burner, in which case, a small hand-held flame was applied directly to the hot end of the sample. Similarly in the RIFT test, a small hand-held flame was applied to the bottom of the hot end of the sample if it did not ignite within the pre-heating time. The time to ignition and the time taken for the flame front to reach marked gridlines located along the centreline of the sample were recorded. The test was complete once the flame ceased to advance along the sample and extinguished.

Natural woods showed variation in the results between tests of identical materials due to grain, knots or other features in the wood. The results for manufactured board were generally consistent between tests on the same material, as expected from their more uniform composition. Flame spread rates along natural woods were generally higher than for the manufactured boards. The test conditions and material properties obtained from the LIFT and RIFT are given in Table 2 and Table 3. The exposure heat flux is defined as $\dot{q}_{50 \mathrm{~mm}}^{\prime \prime}$ in the LIFT and the received heat flux at the end of the sample closest to the cone heater in the RIFT. Values for the minimum heat flux for flame spread $\dot{q}_{s}^{\prime \prime}$ are reported as the average measured value from the extent of flame spread and the value determined from the best fit line respectively.

\subsection{Results for manufactured boards}

\subsubsection{Medium density fibreboard}

Medium Density Fibreboard (MDF) is a panel product frequently used for cabinetry. It is made from wood fibre, which is exploded with steam before being compressed with a pressure cured adhesive to form a flat, stable wood panel [25]. The MDF used in these tests was $18 \mathrm{~mm}$ "Customwood" made by Fletcher Wood Panels (FWP). The extent of flame spread along the sample is shown in Figure $7 \mathrm{a}$ and the flame spread correlations for the LIFT and RIFT are compared in Figure 7b. The RIFT and LIFT produce similar results for the slope of the data fit line, which leads to similar flame spread parameter values shown in Table 2. 


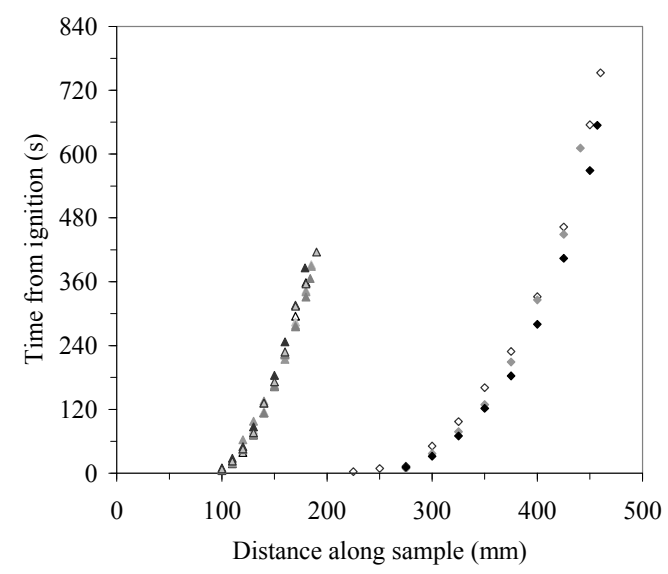

(a)

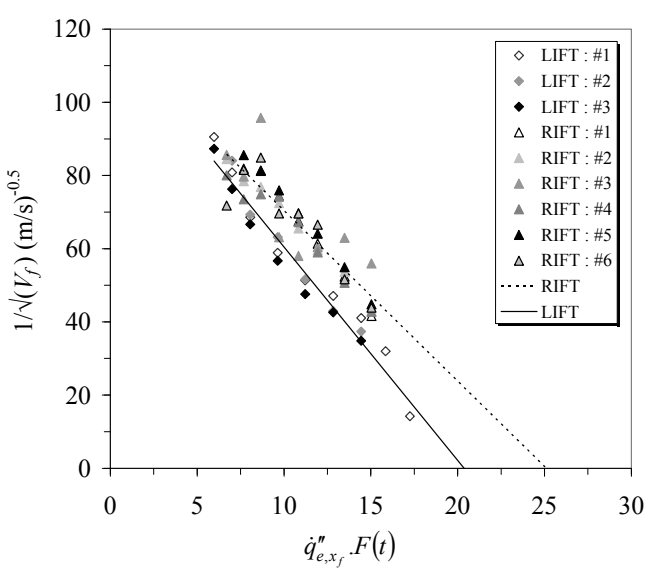

(b)

Figure 7: MDF flame spread (a) measurements; (b) correlation.

\subsubsection{Particle Board}

Particle board is made from wood chips held together with a pressure cured adhesive and is commonly used for flooring and as a substrate for kitset furniture. As particle board is a common material used for research in the literature, two brands of $20 \mathrm{~mm}$ thick Radiata Pine based particle board were tested in the RIFT to examine the variation within a material. The denser 'Pynefloor' board uses a polymerised urea formaldehyde adhesive (up to $15 \%$ of the board content) to give weather resistance during construction, whereas the less dense 'Superflake' board uses a melamine urea formaldehyde adhesive (up to $13 \%$ of the board content) and is for internal use.

A comparison of the flame spread between the two brands of particle board in the RIFT shows only a minor difference in the flame spread rate (Figure 8a), which has little effect on the derived flame spread properties. When the flame spread properties for Pynefloor from the RIFT are compared to those obtained in the LIFT (Figure $8 b$ ) there are noticeable differences in the flame spread parameter and the minimum ignition flux (Table 2). The Superflake board was not tested in the LIFT as there was insufficient material to conduct a full suite of LIFT tests.

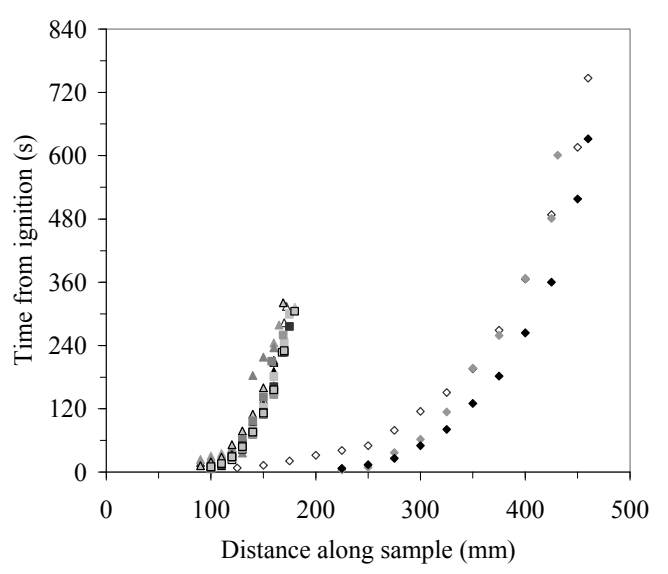

(a)

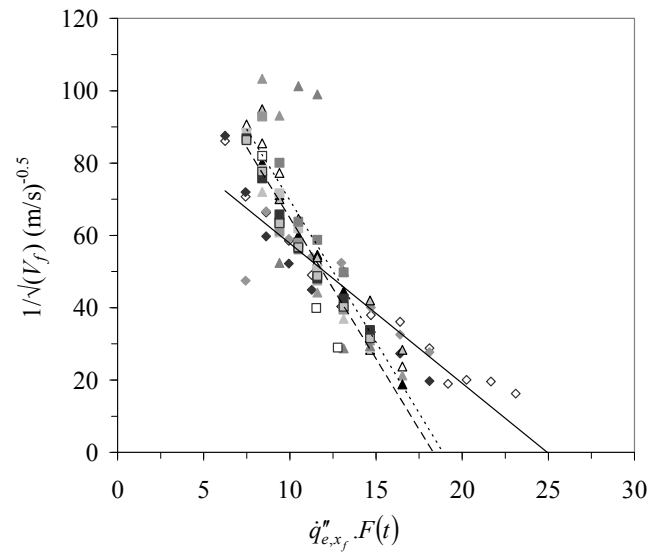

$\diamond$ LIFT : Pynefloor \#1

LIFT : Pynefloor \#2

LIFT : Pynefloor \#3

RIFT : Pynefloor \#

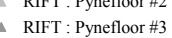

RIFT : Pynefloor \#4

RIFT : Pynefloor \#5

$\triangle$ RIFT : Pynefloor \#6

RIFT : Superflake \#1

RIFT : Superflake $\# 3$

RIFT : Superflake \#4

- RIFT : Superflake \#5

RIFT : Superflake \#6

- RIFT : Superflake

$\cdots .-$ RIFT : Pynefloor
- LIFT : Pynefloor

Figure 8: Particle board flame spread (a) measurements; (b) correlation. 


\subsubsection{Plywood}

Plywood is made from layers of wood, with the grain direction of each ply at 90 degrees to the neighbouring plies, and the layers are joined with a pressure cured adhesive. One face is sanded and surface knots are secured or filled while the other face is rough and empty knots are allowed. Plywood can have varying properties, depending on the substrate and surface plies used and the presence of any voids in the material. All samples were from a single sheet of IPL "Tuffply" $17 \mathrm{~mm}$ untreated Radiata Pine C/D grade plywood. The smooth (C grade) face was used for the flame spread tests. The resulting flame spread along the sample shown in Figure 9a and the flame spread correlations is shown in Figure 9b. Table 2 shows that the flame spread correlation and minimum ignition flux obtained from the RIFT and LIFT are similar, however the RIFT has more data scatter than the LIFT.

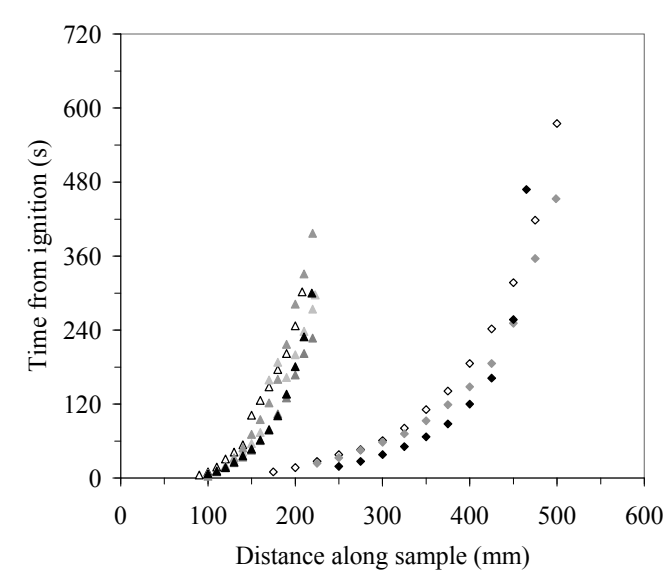

(a)

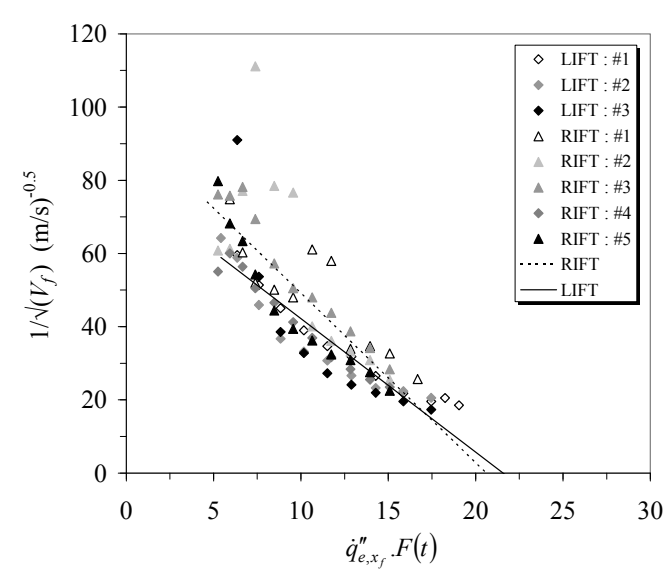

(b)

Figure 9: Plywood flame spread (a) measurements; (b) correlation.

\subsubsection{Hardboard}

Hardboard is a compressed fibreboard sheet product, made from wood pulp and fibres, which is exploded with pressure and steam. This is then compressed using a thermosetting adhesive to form a thin, high density board [25], with a characteristic brown colour. It is commonly used for low strength applications such as cupboard backs and drawer bottoms. A common brand name which is often used as a generic name for this type of hardboard is Masonite. The material used here was a generic unbranded material from a builders supply merchant, with a thickness of $5 \mathrm{~mm}$.

A particular problem with the hardboard experiments was the long pre-heating time of almost 20 mins dictated by the ISO 5657 ignition apparatus results. This pre-heating duration severely charred RIFT test samples which prevented the collection of meaningful flame spread measurements. Instead, the pre-heating time used in both the LIFT and RIFT was the almost 10 mins calculated from the LIFT ignition tests although the ' $b$ ' value obtained in the ISO 5657 ignition test was used to determine the flame spread parameter for the RIFT. Five repeat runs were conducted in the RIFT using the LIFT pre-heating time. During the tests it was found that the 
material cracked behind the flame front area which allowed the pyrolised material to open and allowed flames to the rear of the sample. In spite of this behaviour during pre-heating and burning, consistent flame spread results were obtained in the RIFT and LIFT (Figure 10a) and similar flame spread properties were obtained (Table 2). The data scatter in the correlation (Figure 10b) increases at the lower heat fluxes most likely due to the behaviour of the material during the tests.

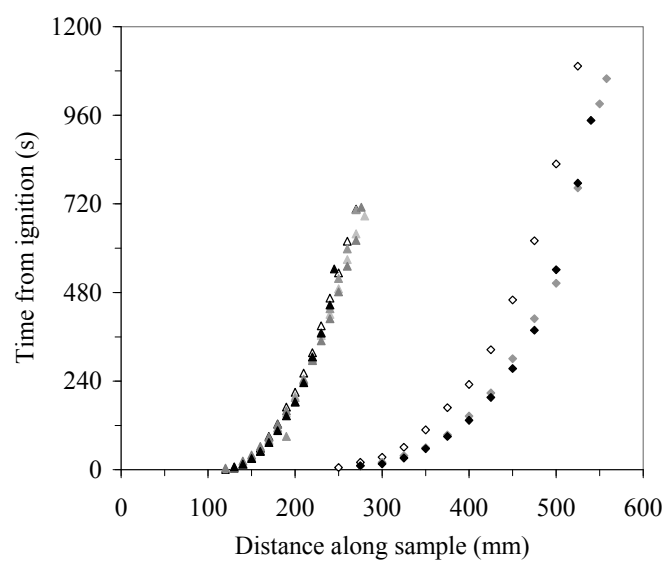

(a)

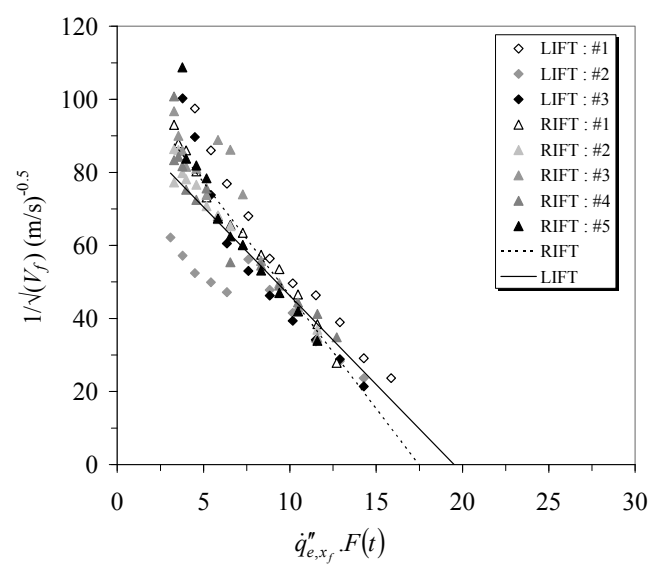

(b)

Figure 10: Hardboard flame spread (a) measurements; (b) correlation.

\subsubsection{Melteca faced board}

Melteca consists of melamine facing on a substrate and is commonly used for shelving, kitchen cabinets, cupboards and bench tops. Two brands of Melteca faced board were tested, where one used a MDF substrate, and the other used particle board. The manufacturer of each board was different so some variation in the performance of the samples due to the differences of the facing material was expected. Only the Melteca faced MDF board was tested in the LIFT due to the amount of material available. The results from the RIFT tests and the Melteca faced MDF board results from the LIFT indicated that further testing in the LIFT of the Melteca faced particle board material was not required due to the inconsistent flame spread results. Six samples of each material were tested in the RIFT.

The ignition and flame spread behaviour of Melteca showed the facing material starts to bubble at relatively low heat fluxes, insulating the substrate material. The flame front only progresses as the facing peeled off or the bubbles split, allowing the pyrolised substrate to escape, and this gave erratic flame spread rates and ignition times. The effect of the substrate can be seen in Figure 11, where the MDF based board has a slower flame spread rate than the particle board based material. Figure 11 also indicates that the surface material had a significant effect as the difference between the two Melteca-faced board types is greater than that of the equivalent unfaced substrate board. 


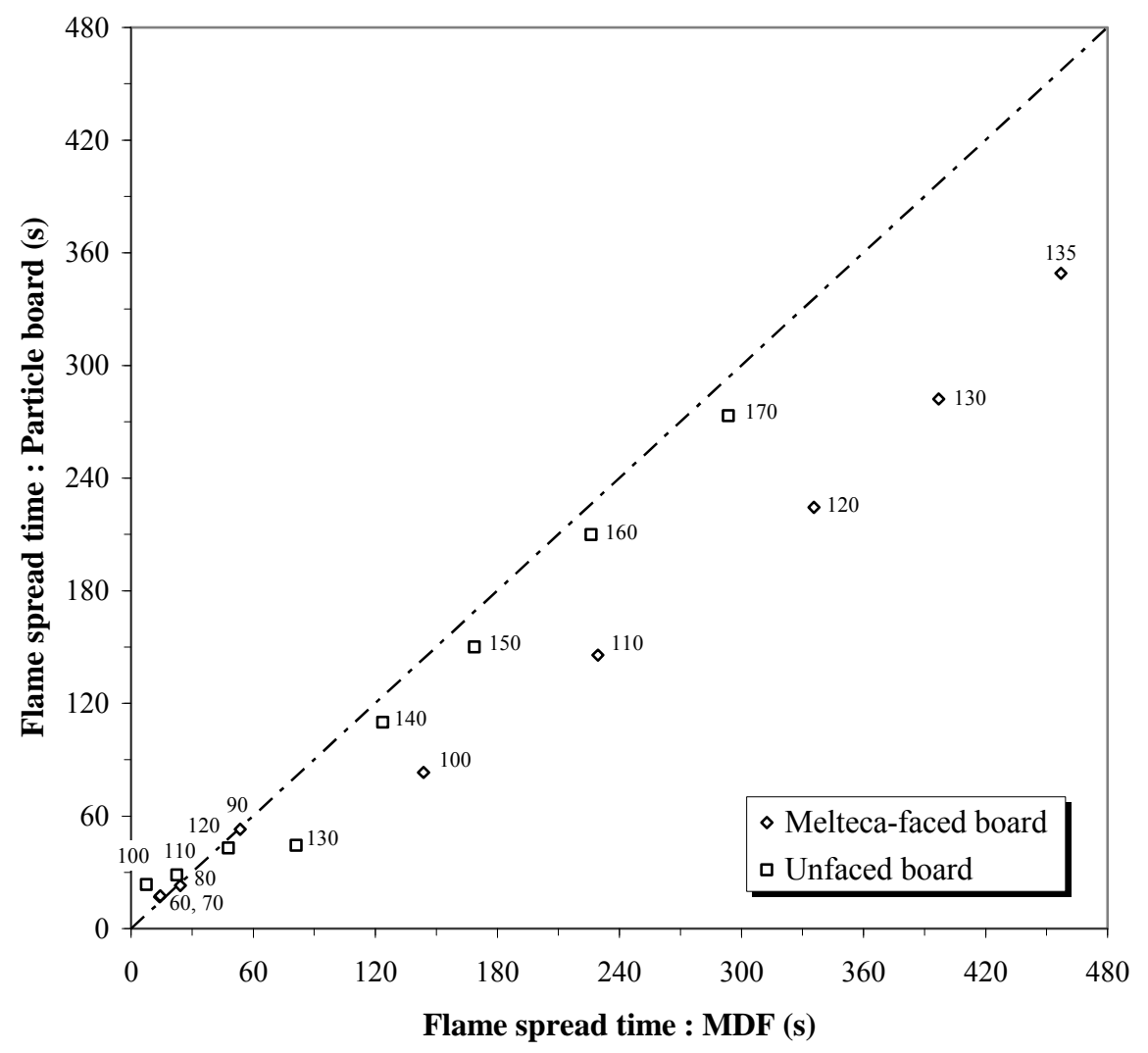

Figure 11: Mean flame spread times to specified distances (in $\mathbf{m m}$ ) using the RIFT for MDF versus particle board, with and without Melteca facing.

It is apparent from the tests on the Melteca-faced boards that having a layer with a higher minimum ignition flux over the comparatively more flammable substrate gives inconsistent results in the LIFT tests and these results are even more scattered in the RIFT (Figure 12) due to the smaller scale and more rapid decay of the flux profile. Although the flame spread measurements obtained for the Melteca-faced boards showed significant variability, the resultant flame spread parameters and minimum ignition fluxes are reasonably consistent as shown in Table 2. 


\begin{tabular}{|c|c|c|c|}
\hline Product & Property & LIFT & RIFT \\
\hline \multirow{5}{*}{ 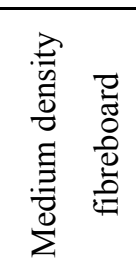 } & Ignition parameter, $b\left[\mathrm{~s}^{-1 / 2}\right]$ & 0.047 & 0.053 \\
\hline & Exposure heat flux $\left[\mathrm{kW} \cdot \mathrm{m}^{-2}\right]$ & 24.2 & 34.9 \\
\hline & Flame spread parameter, $\phi\left[\mathrm{kW}^{2} / \mathrm{m}^{3}\right]$ & 17.1 & 20.8 \\
\hline & Min. ignition flux, $\dot{q}_{i g, \min }^{\prime \prime}\left[\mathrm{kW} \cdot \mathrm{m}^{-2}\right]$ & 20.4 & 25.1 \\
\hline & Min. heat flux for flame spread ${ }^{1}, \dot{q}_{s}^{\prime \prime}\left[\mathrm{kW} . \mathrm{m}^{-2}\right]$ & $5.9 / 6.0$ & $6.3 / 6.7$ \\
\hline \multirow{5}{*}{$\begin{array}{l}\overrightarrow{0} \\
0 \\
\vdots \\
\vdots \\
\end{array}$} & Ignition parameter, $b\left[\mathrm{~s}^{-1 / 2}\right]$ & 0.058 & 0.048 \\
\hline & Exposure heat flux $\left[\mathrm{kW} \cdot \mathrm{m}^{-2}\right]$ & 22.2 & 37.1 \\
\hline & Flame spread parameter, $\phi\left[\mathrm{kW}^{2} / \mathrm{m}^{3}\right]$ & 28.0 & 25.6 \\
\hline & Min. ignition flux, $\dot{q}_{i g, \min }^{\prime \prime}\left[\mathrm{kW} \cdot \mathrm{m}^{-2}\right]$ & 21.6 & 20.6 \\
\hline & Min. heat flux for flame spread ${ }^{1}, \dot{q}_{s}^{\prime \prime}\left[\mathrm{kW} \cdot \mathrm{m}^{-2}\right]$ & $5.3 / 5.4$ & $4.7 / 5.9$ \\
\hline \multirow{5}{*}{ 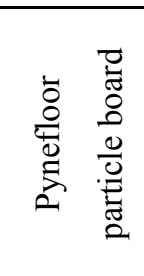 } & Ignition parameter, $b\left[\mathrm{~s}^{-1 / 2}\right]$ & 0.051 & 0.036 \\
\hline & Exposure heat flux $\left[\mathrm{kW} \cdot \mathrm{m}^{-2}\right]$ & 26.0 & 34.9 \\
\hline & Flame spread parameter, $\phi\left[\mathrm{kW}^{2} / \mathrm{m}^{3}\right]$ & 32.8 & 15.6 \\
\hline & Min. ignition flux, $\dot{q}_{i g, \min }^{\prime \prime}\left[\mathrm{kW} \cdot \mathrm{m}^{-2}\right]$ & 24.9 & 18.9 \\
\hline & Min. heat flux for flame spread ${ }^{1}, \dot{q}_{s}^{\prime \prime}\left[\mathrm{kW} \cdot \mathrm{m}^{-2}\right]$ & $6.3 / 6.2$ & $7.6 / 7.5$ \\
\hline \multirow{5}{*}{ 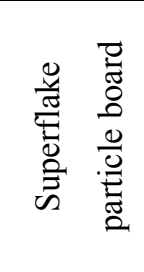 } & Ignition parameter, $b\left[\mathrm{~s}^{-1 / 2}\right]$ & \multirow{5}{*}{$\begin{array}{l}\overrightarrow{0} \\
0 \\
0 \\
0 \\
0 \\
0\end{array}$} & 0.033 \\
\hline & Exposure heat flux $\left[\mathrm{kW} \cdot \mathrm{m}^{-2}\right]$ & & 34.9 \\
\hline & Flame spread parameter, $\phi\left[\mathrm{kW}^{2} / \mathrm{m}^{3}\right]$ & & 19.6 \\
\hline & Min. ignition flux, $\dot{q}_{i g, \min }^{\prime \prime}\left[\mathrm{kW} \cdot \mathrm{m}^{-2}\right]$ & & 18.3 \\
\hline & Min. heat flux for flame spread ${ }^{1}, \dot{q}_{s}^{\prime \prime}\left[\mathrm{kW} \cdot \mathrm{m}^{-2}\right]$ & & $7.4 / 7.5$ \\
\hline \multirow{5}{*}{ 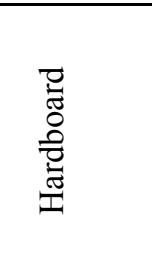 } & Ignition parameter, $b\left[\mathrm{~s}^{-1 / 2}\right]$ & 0.041 & 0.029 \\
\hline & Exposure heat flux $\left[\mathrm{kW} \cdot \mathrm{m}^{-2}\right]$ & 22.2 & 35.1 \\
\hline & Flame spread parameter, $\phi\left[\mathrm{kW}^{2} / \mathrm{m}^{3}\right]$ & 32.1 & 39.5 \\
\hline & Min. ignition flux, $\dot{q}_{i g, \min }^{\prime \prime}\left[\mathrm{kW} \cdot \mathrm{m}^{-2}\right]$ & 19.5 & 17.5 \\
\hline & Min. heat flux for flame spread ${ }^{1}, \dot{q}_{s}^{\prime \prime}\left[\mathrm{kW} \cdot \mathrm{m}^{-2}\right]$ & $3.4 / 3.1$ & $3.2 / 3.3$ \\
\hline \multirow{5}{*}{ 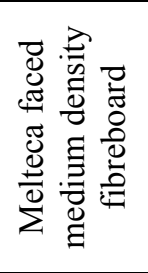 } & Ignition parameter, $b\left[\mathrm{~s}^{-1 / 2}\right]$ & 0.042 & 0.043 \\
\hline & Exposure heat flux $\left[\mathrm{kW} \cdot \mathrm{m}^{-2}\right]$ & 35.7 & 35.6 \\
\hline & Flame spread parameter, $\phi\left[\mathrm{kW}^{2} / \mathrm{m}^{3}\right]$ & 41.6 & 16.7 \\
\hline & Min. ignition flux, $\dot{q}_{i g, \min }^{\prime \prime}\left[\mathrm{kW} \cdot \mathrm{m}^{-2}\right]$ & 33.4 & 30.7 \\
\hline & Min. heat flux for flame spread ${ }^{1}, \dot{q}_{s}^{\prime \prime}\left[\mathrm{kW} \cdot \mathrm{m}^{-2}\right]$ & $9.9 / 10.9$ & $14.0 / 11.5$ \\
\hline \multirow{5}{*}{ 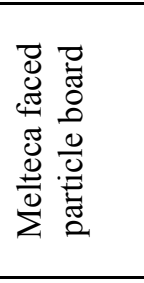 } & Ignition parameter, $b\left[\mathrm{~s}^{-1 / 2}\right]$ & \multirow{5}{*}{$\begin{array}{l}\overrightarrow{0} \\
\overrightarrow{0} \\
0 \\
0 \\
0 \\
z\end{array}$} & 0.044 \\
\hline & Exposure heat flux $\left[\mathrm{kW} \cdot \mathrm{m}^{-2}\right]$ & & 35.6 \\
\hline & Flame spread parameter, $\phi\left[\mathrm{kW}^{2} / \mathrm{m}^{3}\right]$ & & 29.2 \\
\hline & Min. ignition flux, $\dot{q}_{i g, \min }^{\prime \prime}\left[\mathrm{kW} \cdot \mathrm{m}^{-2}\right]$ & & 31.3 \\
\hline & Min. heat flux for flame spread ${ }^{1}, \dot{q}_{s}^{\prime \prime}\left[\mathrm{kW} \cdot \mathrm{m}^{-2}\right]$ & & $11.6 / 9.6$ \\
\hline
\end{tabular}

${ }^{1}$ From extent of flame spread / correlation

Table 2. Flame spread properties for manufactured boards. 


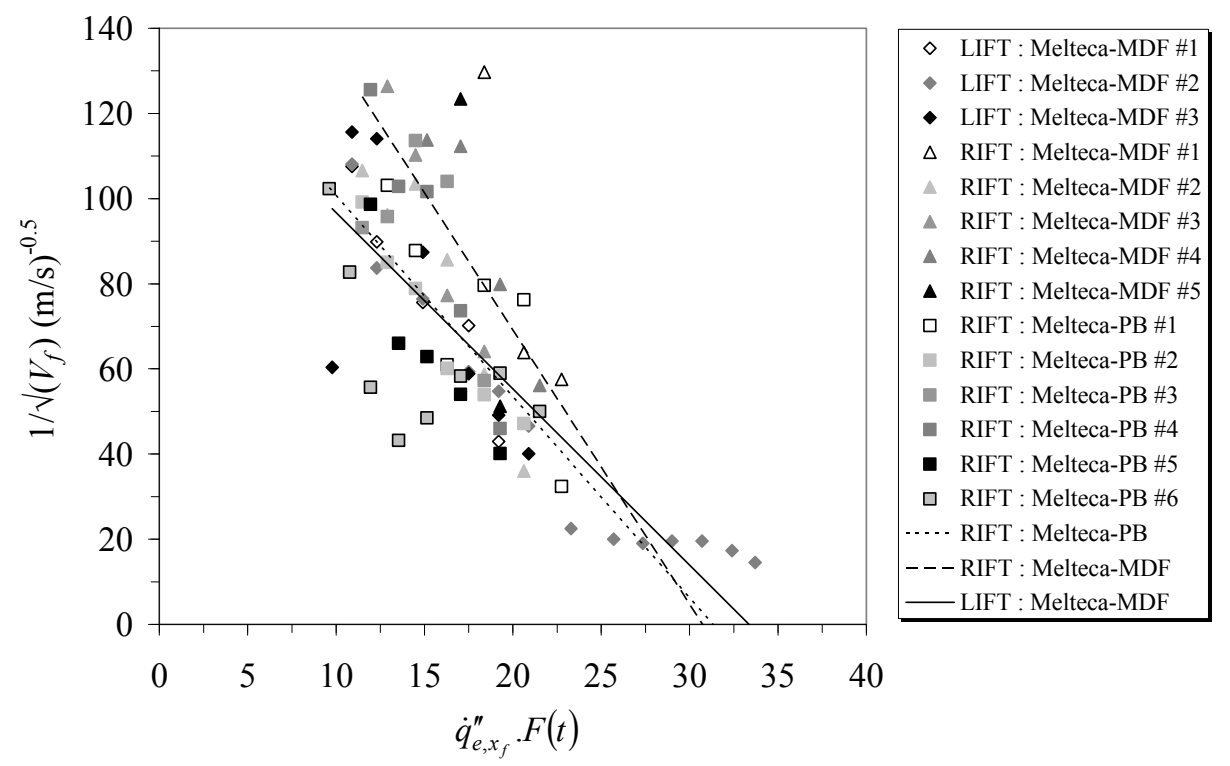

Figure 12: Flame spread correlations for Melteca-faced boards.

\subsection{Results for natural woods}

\subsubsection{Beech}

New Zealand Beech belongs to the family of southern Beech trees native to the southern hemisphere. The flame spread showed wide variations between runs in the RIFT (Figure 13a) and the flame spread correlation for the RIFT is compared with the LIFT in Figure 13b. The resulting flame spread correlation shows some curvature in the fit of the data, indicating that the material may not have reached thermal equilibrium, despite being preheated to the time given by the ignition results. The RIFT and LIFT gave similar results for the flame spread correlation (Table 3 ) and the results for the correlated values for the minimum heat flux for flame spread and the minimum ignition flux are similar for both methods.

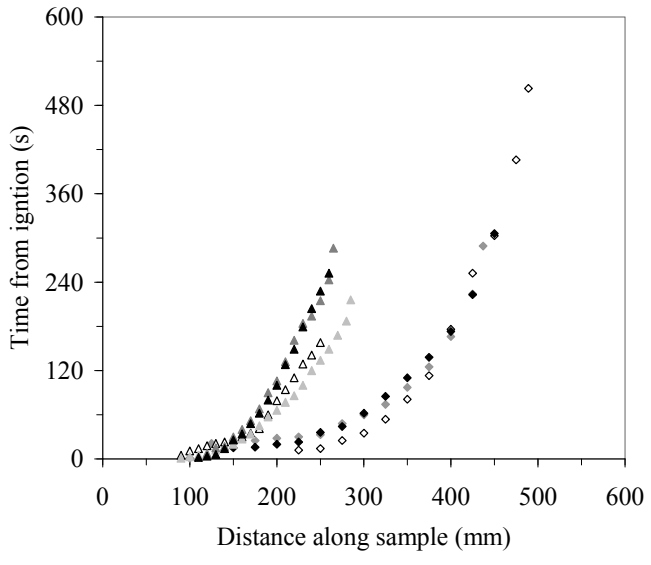

(a)

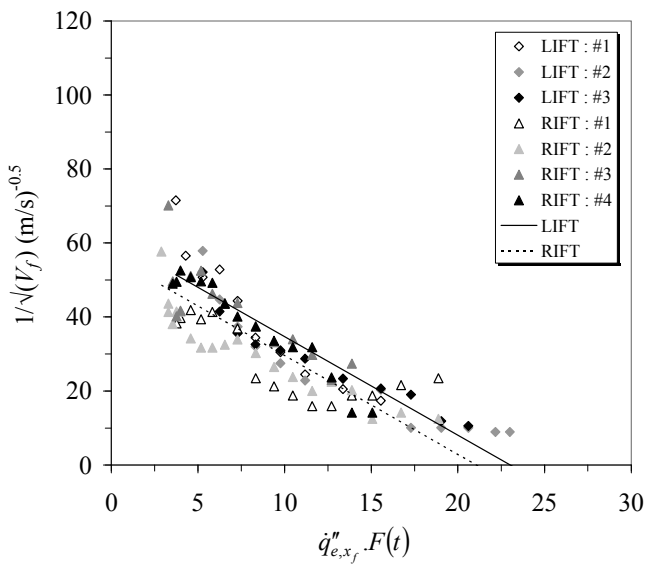

(b)

Figure 13: Beech flame spread (a) measurements; (b) correlation. 


\subsubsection{Macrocarpa}

Macrocarpa is a member of the cypress family, and is also known in the US as Monterey cypress. The wood is used for boat building, furniture, framing and panelling. It is prone to sparking when burning due to the resinous streaks which can make the flame spread erratic, as the flame front tends to follow a resin streak on the face of the wood, rather than spreading evenly over the face of the material seen in the variation of the flame spread results between runs in Figure 14a particularly towards the end of the sample.

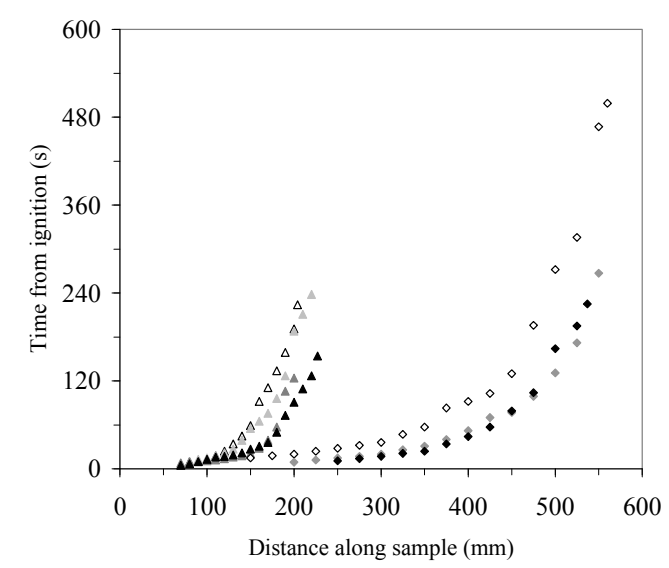

(a)

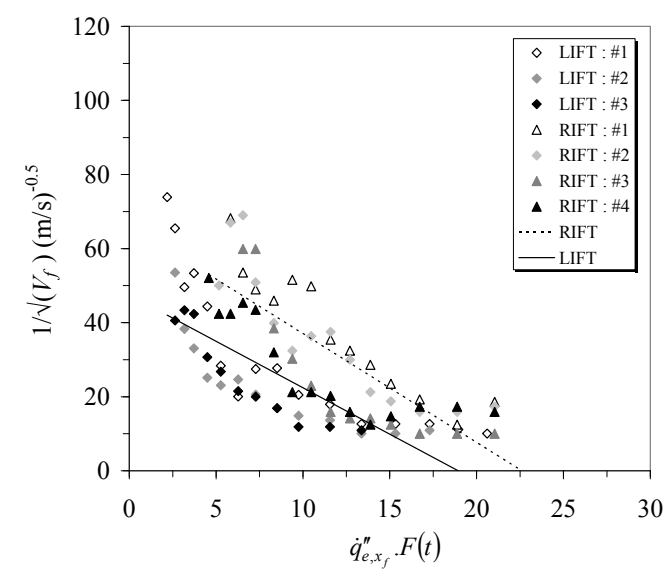

(b)

Figure 14: Macrocarpa flame spread (a) measurements; (b) correlation.

The resulting flame spread correlation for the RIFT results shows significant data scatter (Figure 14b). The curve to the LIFT results in the flame spread correlation indicates that the material was not pre-heated sufficiently, based on the work by Quintiere et al. [9] despite the pre-heating time coming from the LIFT ignition results. Despite the scatter in the data, flame spread properties from the two test apparatus are similar (Table 3).

\subsubsection{Radiata Pine}

Radiata Pine is a native of California, and is also known there as Monterey Pine. It forms the basis of New Zealand silviculture, making up $95 \%$ of the New Zealand timber production in 2004. It forms the basis of almost all New Zealand made framing timber and manufactured wood panels. The board noticeably charred during the pre-heating period, and the area up to $180 \mathrm{~mm}$ along the sample was difficult to ignite just by using the pilot flame. The flame spread (Figure 15a) for Radiata Pine shows less variation than some of the other natural woods tested. The more consistent flame spread behaviour gives a more reliable correlation for the flame spread with less scatter in the data. The RIFT gives a similar match for the flame spread correlation (Figure 15b) but with more data scatter. 


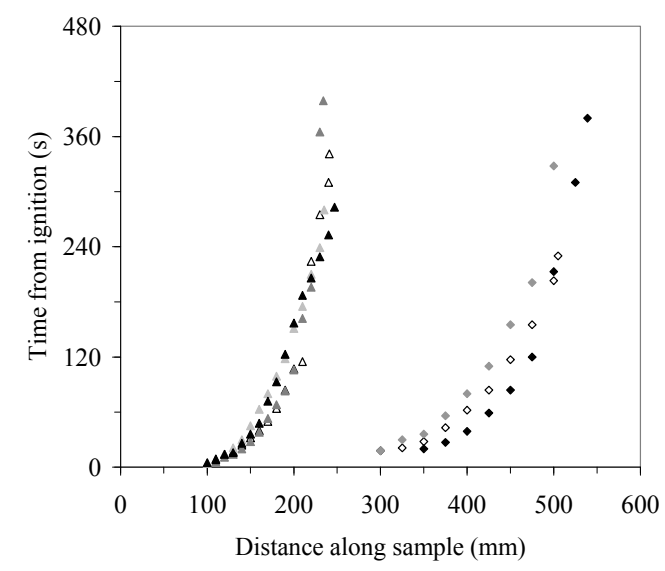

(a)

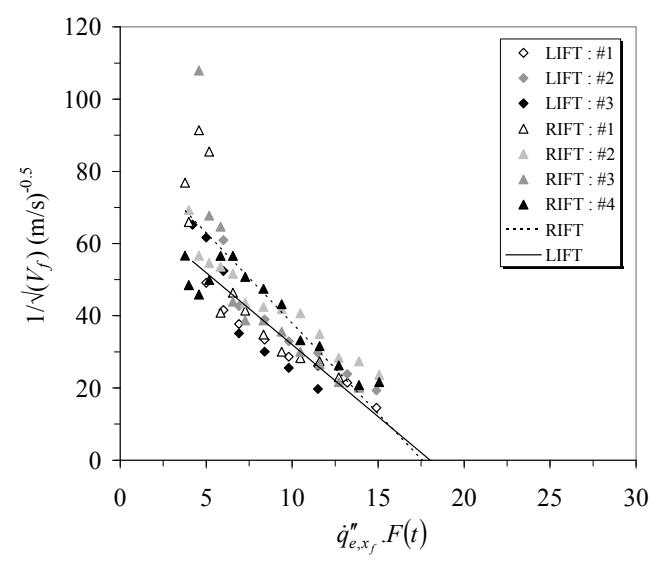

(b)

Figure 15: Radiata Pine flame spread (a) measurements; (b) correlation.

\subsubsection{Rimu}

Rimu is a native New Zealand wood, although other members of the same family are found through the Pacific Rim. It has been widely used for flooring, panelling and furniture making, and was widely used for framing until the introduction of Radiata Pine from the 1960s. It was found that using the ISO 5657 apparatus pre-heating period of $397 \mathrm{~s}$ there was insufficient flame spread in the RIFT to get usable data. The extent of flame spread was in the order of $130 \mathrm{~mm}$; however the initial results for the $90-100 \mathrm{~mm}$ was already significantly charred prior to ignition. A series of additional experiments were conducted using reduced pre-heating times between $67-$ $80 \mathrm{~s}$ to try and obtain sufficient flame spread results.

The measurements are given in Figure 16a and the extent of flame spread in the LIFT showed significant variation, covering a range of over $125 \mathrm{~mm}$. There are significant differences between the flame spread correlations in the RIFT and LIFT (Figure 16b) which result in widely varying flame spread properties (Table 3). These differences may be partly attributed to the need to use the reduced pre-heating time in the RIFT.

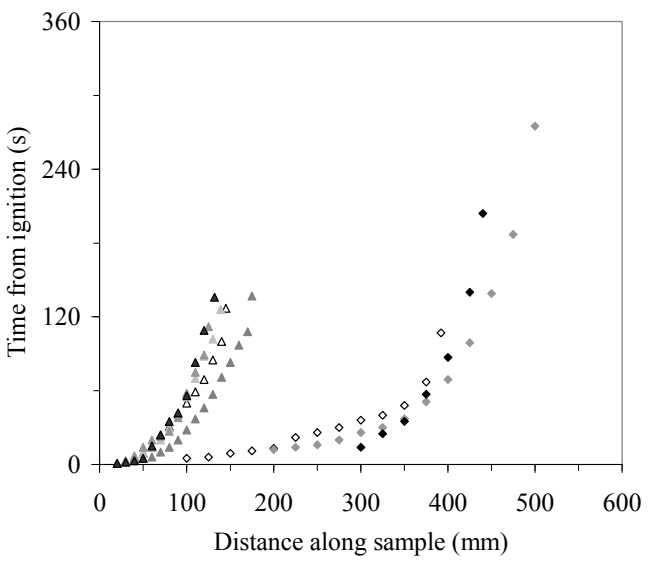

(a)

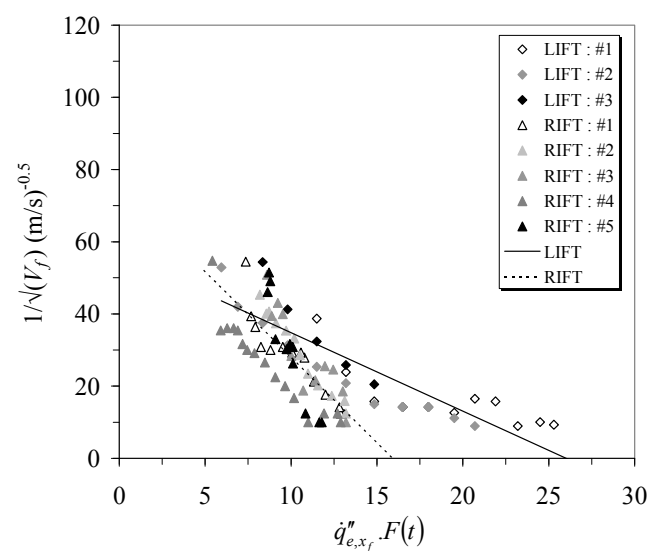

(b)

Figure 16: Rimu flame spread (a) measurements; (b) correlation. 


\begin{tabular}{|c|c|c|c|}
\hline Product & Property & LIFT & RIFT \\
\hline \multirow{5}{*}{$\begin{array}{l}\tilde{J} \\
\mathscr{̋} \\
\infty\end{array}$} & Ignition parameter, $b\left[\mathrm{~s}^{-1 / 2}\right]$ & 0.050 & 0.053 \\
\hline & Exposure heat flux $\left[\mathrm{kW} \cdot \mathrm{m}^{-2}\right]$ & 25.2 & 34.9 \\
\hline & Flame spread parameter, $\phi\left[\mathrm{kW}^{2} / \mathrm{m}^{3}\right]$ & 70.9 & 63.1 \\
\hline & Min. ignition flux, $\dot{q}_{i g, \min }^{\prime \prime}\left[\mathrm{kW} \cdot \mathrm{m}^{-2}\right]$ & 23.0 & 20.5 \\
\hline & Min. heat flux for flame spread ${ }^{1}, \dot{q}_{s}^{\prime \prime}\left[\mathrm{kW} \cdot \mathrm{m}^{-2}\right]$ & $4.4 / 3.7$ & $3.3 / 2.9$ \\
\hline \multirow{5}{*}{ 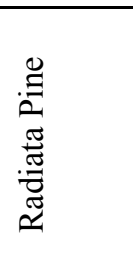 } & Ignition parameter, $b\left[\mathrm{~s}^{-1 / 2}\right]$ & 0.040 & 0.039 \\
\hline & Exposure heat flux $\left[\mathrm{kW} \cdot \mathrm{m}^{-2}\right]$ & 27.0 & 34.9 \\
\hline & Flame spread parameter, $\phi\left[\mathrm{kW}^{2} / \mathrm{m}^{3}\right]$ & 50.2 & 32.6 \\
\hline & Min. ignition flux, $\dot{q}_{i g, \min }^{\prime \prime}\left[\mathrm{kW} \cdot \mathrm{m}^{-2}\right]$ & 18.0 & 17.6 \\
\hline & Min. heat flux for flame spread ${ }^{1}, \dot{q}_{s}^{\prime \prime}\left[\mathrm{kW} \cdot \mathrm{m}^{-2}\right]$ & $4.5 / 4.2$ & $3.8 / 3.8$ \\
\hline \multirow{5}{*}{ 节 } & Ignition parameter, $b\left[\mathrm{~s}^{-1 / 2}\right]$ & 0.037 & 0.050 \\
\hline & Exposure heat flux $\left[\mathrm{kW} \cdot \mathrm{m}^{-2}\right]$ & 26.8 & 34.9 \\
\hline & Flame spread parameter, $\phi\left[\mathrm{kW}^{2} / \mathrm{m}^{3}\right]$ & 196.8 & 22.5 \\
\hline & Min. ignition flux, $\dot{q}_{i g, \min }^{\prime \prime}\left[\mathrm{kW} \cdot \mathrm{m}^{-2}\right]$ & 26.0 & 15.9 \\
\hline & Min. heat flux for flame spread ${ }^{1}, \dot{q}_{s}^{\prime \prime}\left[\mathrm{kW} \cdot \mathrm{m}^{-2}\right]$ & $7.6 / 6.0$ & $11.7 / 5.4$ \\
\hline \multirow{5}{*}{ 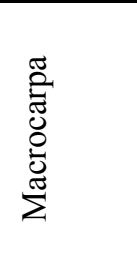 } & Ignition parameter, $b\left[\mathrm{~s}^{-1 / 2}\right]$ & 0.059 & 0.048 \\
\hline & Exposure heat flux $\left[\mathrm{kW} \cdot \mathrm{m}^{-2}\right]$ & 25.2 & 34.9 \\
\hline & Flame spread parameter, $\phi\left[\mathrm{kW}^{2} / \mathrm{m}^{3}\right]$ & 58.3 & 64.5 \\
\hline & Min. ignition flux, $\dot{q}_{i g, \min }^{\prime \prime}\left[\mathrm{kW} \cdot \mathrm{m}^{-2}\right]$ & 18.9 & 22.6 \\
\hline & Min. heat flux for flame spread ${ }^{1}, \dot{q}_{s}^{\prime \prime}\left[\mathrm{kW} \cdot \mathrm{m}^{-2}\right]$ & $2.2 / 2.2$ & $5.0 / 4.6$ \\
\hline
\end{tabular}

${ }^{1}$ From extent of flame spread / correlation

Table 3. Flame spread properties for natural woods.

\section{DISCUSSION}

\subsection{Apparatus}

The narrower $15^{\circ}$ angle and larger scale of the LIFT apparatus means that measurement of the heat flux profile is less sensitive than in the RIFT. The rapid decay of the heat flux along the RIFT sample makes location of the measuring holes critical, as a small change in the position can make a large change in the measured heat flux. It is important when measuring the heat flux that the face of the heat flux gauge is parallel with the face of the template. This is easier to achieve in the RIFT than in the LIFT, as the operator can see the front face of the template although the steeper $60^{\circ}$ sample angle of the RIFT means that, small errors in holding the flux gauge in place can have a large effect.

A problem shared by both the RIFT and the LIFT for directly observing the flame front is the charring of the material during pre-heating. Markings done with a graphite pencil could often still be distinguished even though the surface of the material had blackened. Generally it was found that if the surface was too heavily charred, so that the pencil marks were no longer visible, then flame spread would be too rapid for accurate measurement, or the material would no longer ignite. 


\subsection{Minimum ignition flux}

The comparison of the correlated value and the measured value for the minimum ignition flux $\left(\dot{q}_{i g, \min }^{\prime \prime}\right)$ is shown below for both the RIFT and the LIFT (Figure 17). The values of the minimum ignition flux from the flame spread correlation are consistently higher than the experimental values. Babrauskas and Wetterlund [21] also noted this finding with their results, where they used the LIFT for both the ignition and flame spread tests.

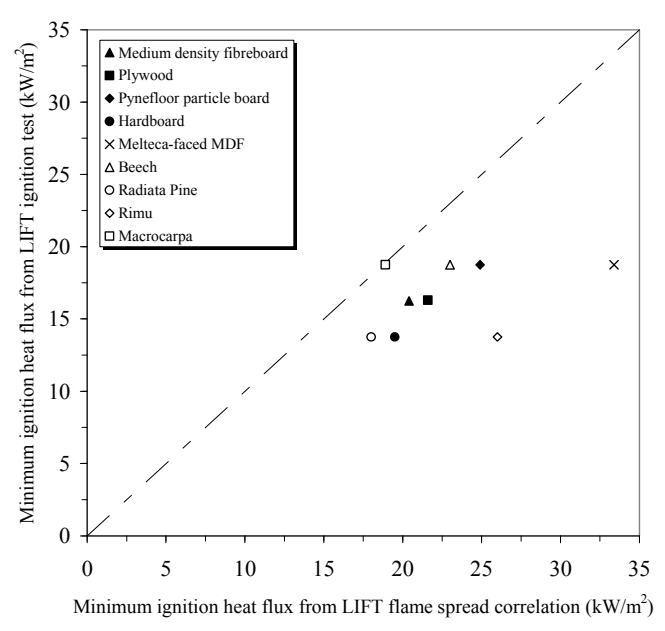

(a)

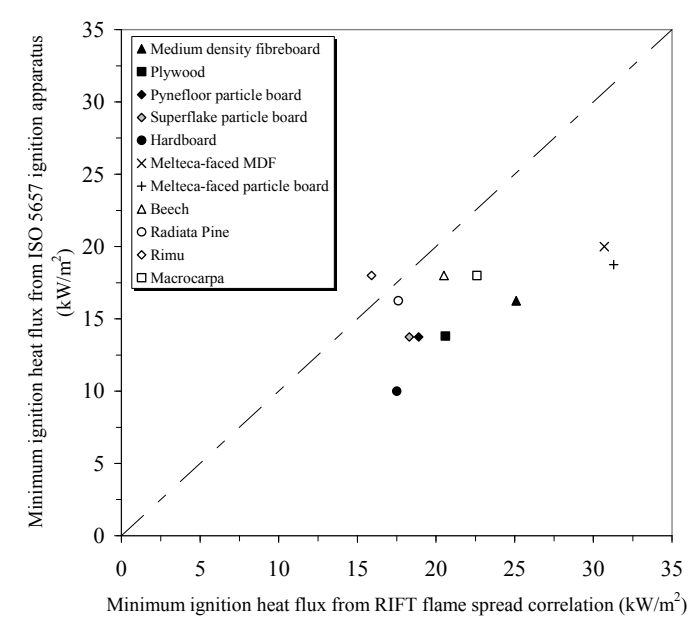

(b)

Figure 17: Comparison of minimum ignition flux (a) LIFT correlation and LIFT ignition test results; (b) RIFT flame spread correlation and ISO 5657 ignition test.

\subsection{Flame spread parameter $\Phi$}

The flame spread parameter depends on the ignition parameter ' $b$ ' value which can vary depending on the experimental apparatus and data reduction analysis. Generally the flame spread parameters calculated from the LIFT tests are higher than those from the same material in the RIFT (Figure 18) and a reasonable match was obtained for several materials tested. Melteca-faced MDF, Radiata Pine and Pynefloor particle board did not compare quite so well while Rimu (not shown) gave a very poor match. 


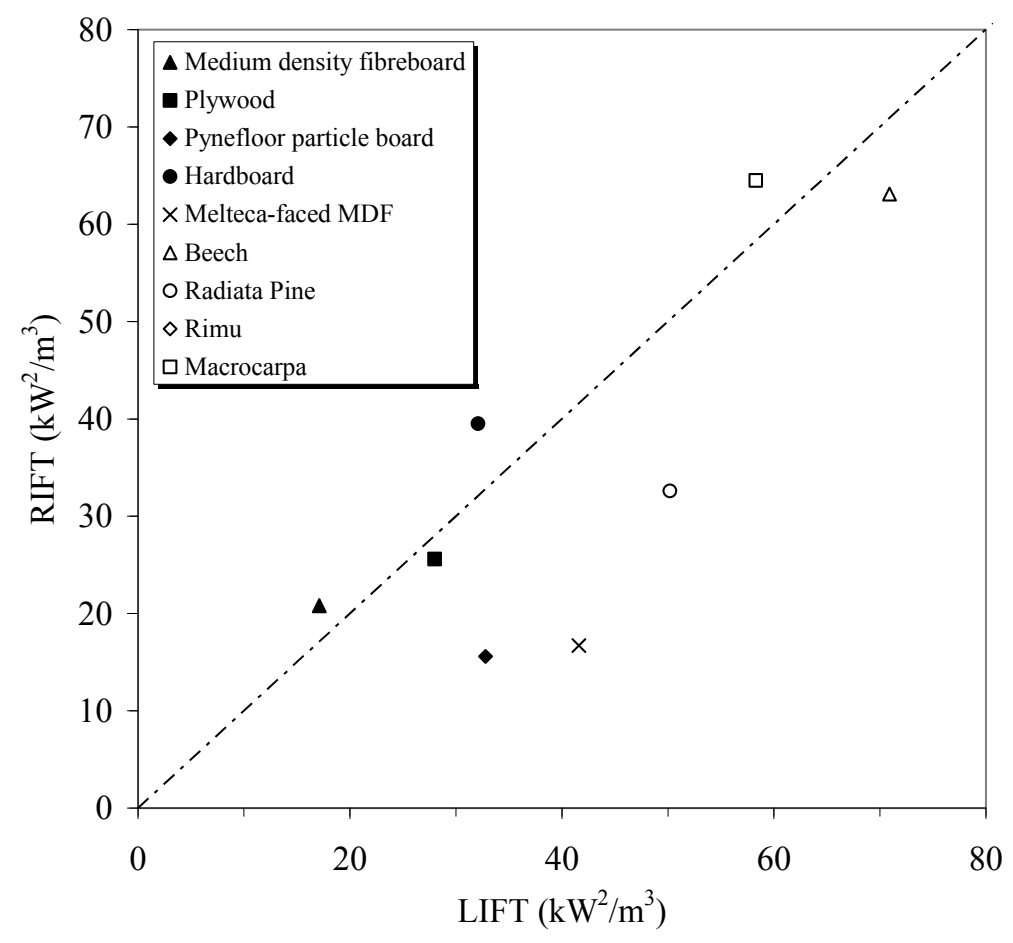

Figure 18: Comparison between flame spread parameter for LIFT and RIFT (Rimu not shown).

\subsection{Minimum heat flux for flame spread}

A limiting factor to the RIFT test is the minimum flux required for flame spread $\left(\dot{q}_{s}^{\prime \prime}\right)$ as if this value is too high there is likely to be insufficient flame spread along the sample to give useable data. As the initial $80 \mathrm{~mm}$ of most wood based samples in the RIFT was unusable due to charring during the pre-heating period, the practical limit in order to get sufficient data were flame spread distances along to $180 \mathrm{~mm}$ from the hot end of the sample. The rapid decay of the heat flux profile around this point made measurement of the flame spread velocity more difficult.

A comparison of the minimum flux required for flame spread results for the LIFT and RIFT are is shown in Figure 19. The outliers of Rimu and Melteca-faced MDF at the upper end of the scale are largely because the flame spread stops in the area where the profile is rapidly diminishing with a change of $4 \mathrm{~kW} / \mathrm{m}^{2}$ over the $25 \mathrm{~mm}$ measuring interval of the heat flux measuring template. The results where there is a closer match between materials are when $\dot{q}_{s}^{\prime \prime}<7 \mathrm{~kW} / \mathrm{m}^{2}$, suggesting this might be used as a practical limit to the RIFT test to get comparable results. This limit depends on the flame spread behaviour of the material, and the effect of charring due to the pre-heating. If the flame spread rate is sufficiently low, and data can be obtained over the area that is normally too heavily charred to ignite easily, then it may be possible to get useable data above this limit. 


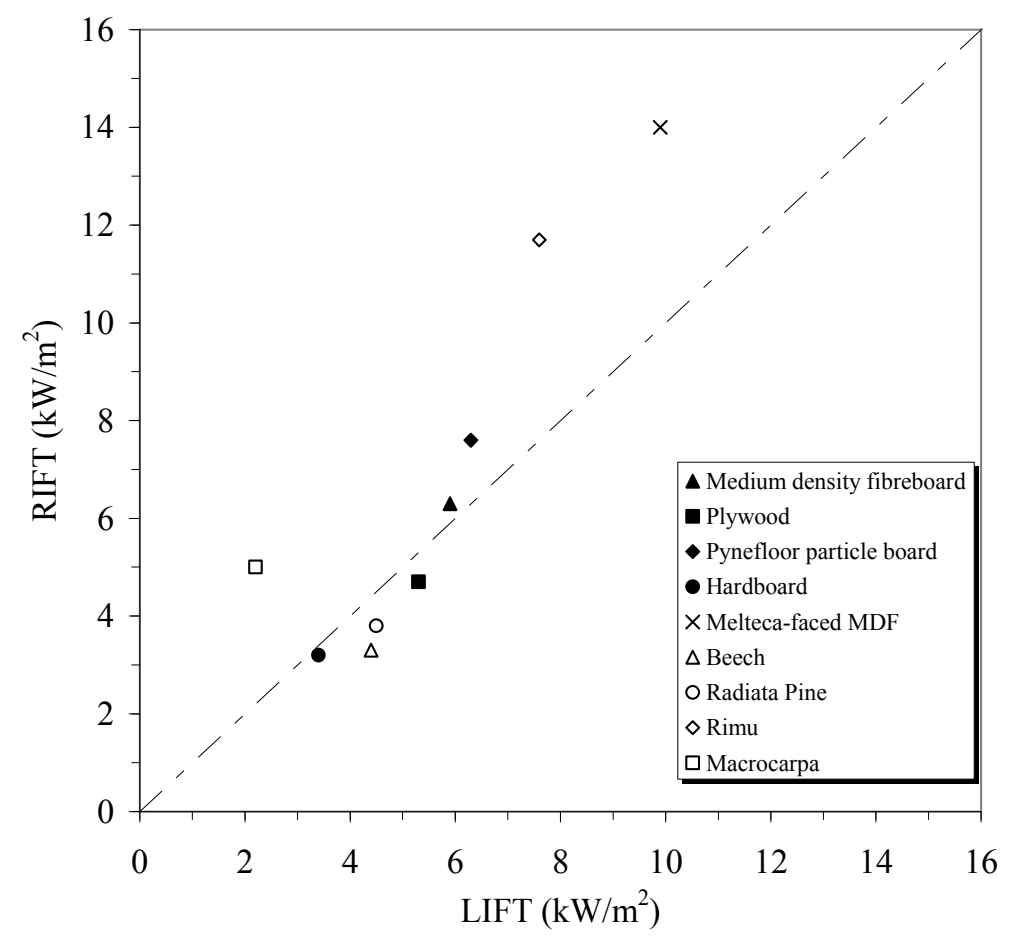

Figure 19: Comparison of minimum flux for flame spread in LIFT and RIFT.

Given that the minimum flux for spread is not known until the material is tested, an estimate of the likelihood of success of the RIFT flame spread test is desirable from the ignition tests. Although a comparison of the minimum ignition flux and the flux required for spread gives a poor correlation in absolute values (Figure 20) it does show a similar trend for the materials. Materials which exhibited very limited flame spread results (the Melteca-faced MDF and Rimu) have the highest minimum ignition flux and this suggests there is an approximate limit for the minimum ignition flux of $\dot{q}_{i g, \min }^{\prime \prime}<18$ to $19 \mathrm{~kW} / \mathrm{m}^{2}$ for a successful flame spread test in the RIFT. 


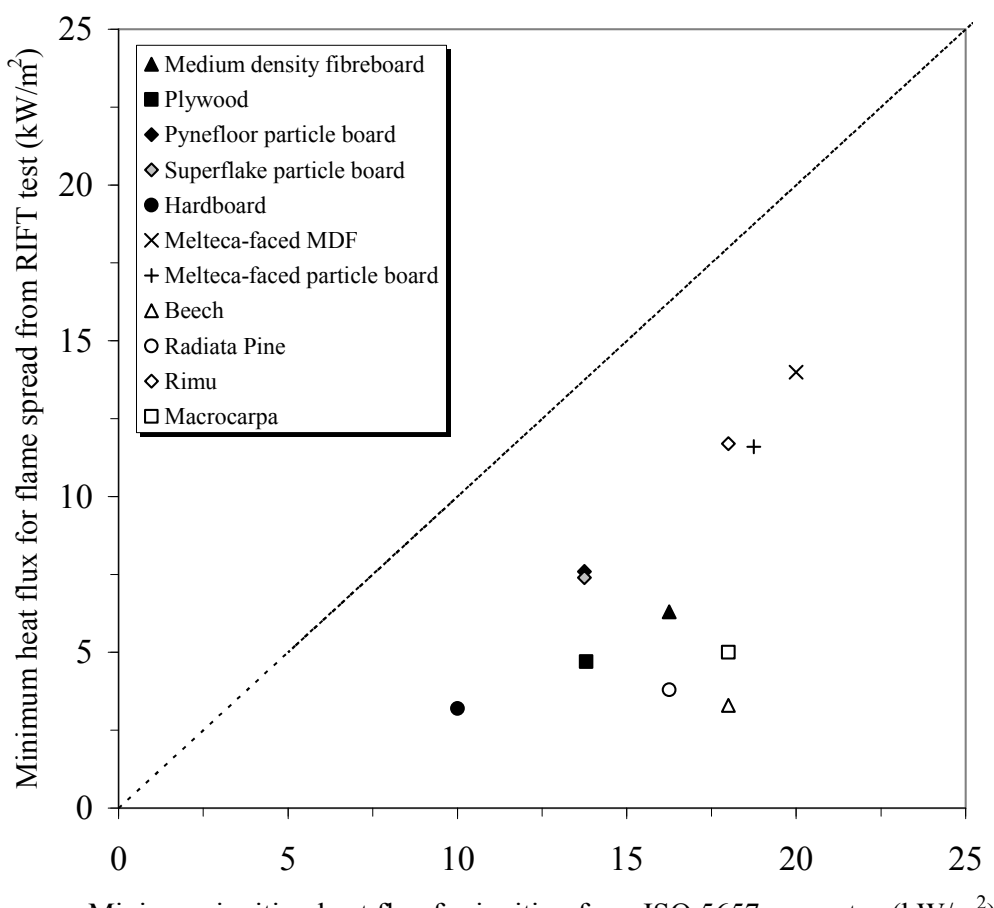

Minimum ignition heat flux for ignition from ISO 5657 apparatus $\left(\mathrm{kW} / \mathrm{m}^{2}\right)$

Figure 20: Minimum ignition flux from ISO 5657 test versus minimum flux for spread for RIFT.

\subsection{Comparison with published literature}

There is little published data available from LIFT flame spread tests, reflecting the narrower focus of the test when compared to the cone calorimeter and even more so when considering New Zealand native woods. Even within materials of the same type or source, the variation can be significant. Comparisons have to be treated with caution, since materials often have a different base for the same nominal material. As an example, the material basis for US construction plywood is given as Douglas fir or Southern Pine for much of the literature while European plywood, where the material details are specified, is birch based. New Zealand plywood is generally Radiata Pine, other than specialty furniture and marine plywood. Similarly "fibreboard" is often poorly defined in the literature and the density and properties of fibreboard products can vary greatly depending on the end use and manufacturing process. While "fibreboard" may refer to MDF, it may also refer to low density fibreboards, of the type commonly used for pinboards and ceiling tiles. As such, the material properties will be different from MDF and will give different test results.

The comparison with the literature is limited to materials approximately the same as those tested for this work, in regard to material composition and surface finish. The results from Huynh [23] should be taken with care, as the correlation obtained by Huynh of the flame spread results was poor, and the material was not pre-heated. The results from Jianmin [26] were calculated using the data given in the report by Jianmin as the flame spread parameter was not specifically stated as an outcome. 


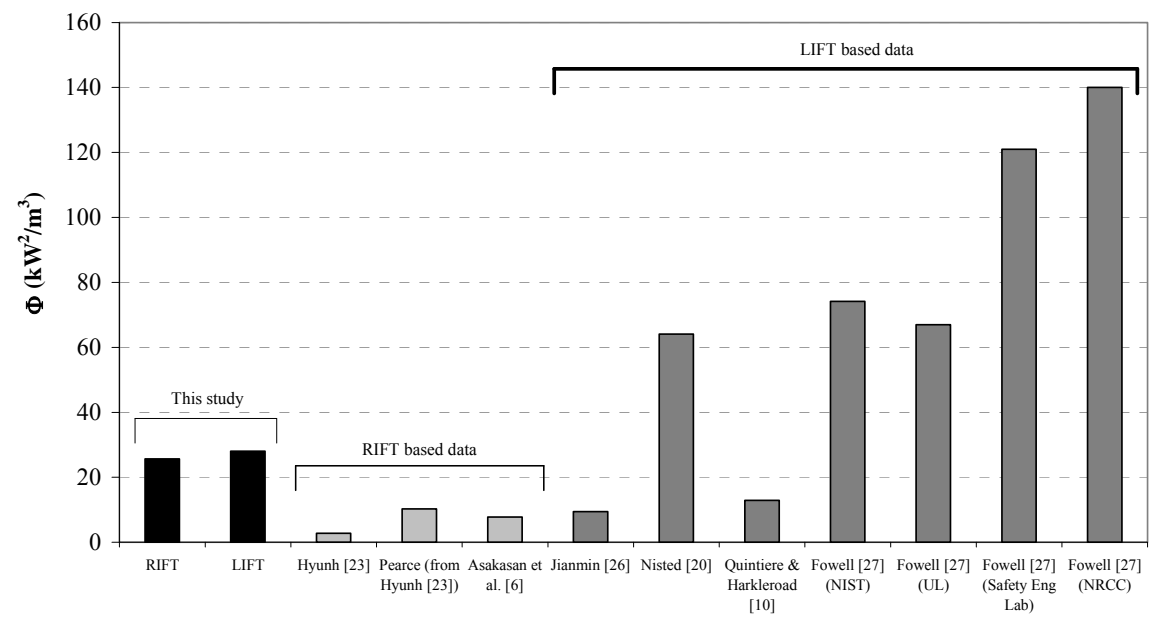

(a)

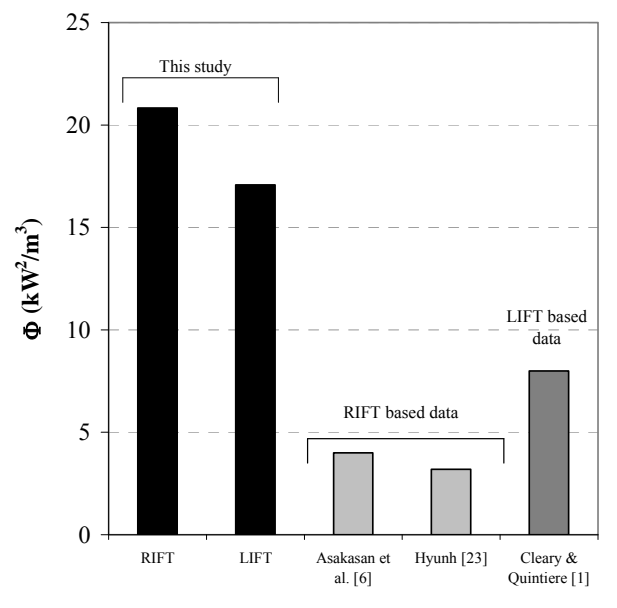

(b)

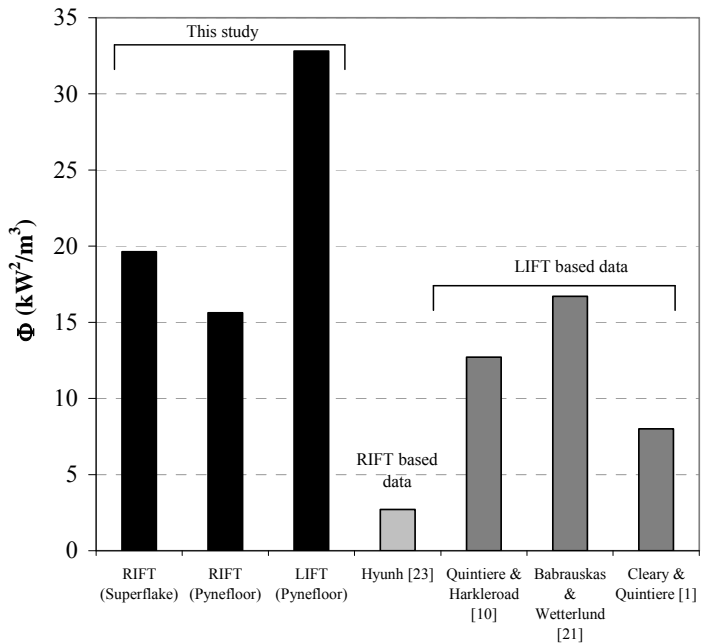

(c)

Figure 21: Flame spread parameter for (a) plywood; (b) MDF; (c) particle board.

Data for plywood show that the flame spread parameter obtained in this work using New Zealand Radiata Pine based plywood (Figure 21a) are generally lower than published values in the literature for plywood tested in the LIFT but higher than those tested in the RIFT. The results for medium density fibreboard are shown in Figure $21 \mathrm{~b}$ and although similar results were obtained from the LIFT and RIFT in this work, values are greater than reported elsewhere. The material specified as "fibreboard" by Azhakesan et al. [6] is not clearly defined as MDF as no density information was given. Azhakesan et al. [6] commented that their flame spread parameter was lower than their expected value of around $13 \mathrm{~kW}^{2} / \mathrm{m}^{3}$. Particle board is a commonly tested material in the LIFT literature, and much of the initial work on developing the theory was based on results for this material $[8,9,10]$. The results (Figure 21c) for the RIFT are similar to the published data, but less than the results from the LIFT 
with the same material. The particle board used by Quintiere and Harkleroad [10] was Douglas Fir based whilst the wood species used by Babrauskas and Wetterlund [21] were not identified.

\section{CONCLUSIONS}

An ASTM E 1321 Lateral ignition and Flame Transport (LIFT) apparatus was constructed and a reduced scale ignition and flame spread apparatus (RIFT) was built to fit the cone calorimeter in the vertical position. The LPG fuelled burner in the LIFT was proven to give a consistent output and although the current air supply limited the burner output to a maximum sustained output of $50 \mathrm{~kW} / \mathrm{m}^{2}$ at the sample face, tests have shown that over $60 \mathrm{~kW} / \mathrm{m}^{2}$ is possible. By adjusting the burner away from the sample a minimum incident heat flux of $11 \mathrm{~kW} / \mathrm{m}^{2}$ was obtained while still maintaining a stable burner output.

The flame spread parameters calculated from the RIFT tests using the ISO ignition data were generally comparable to those obtained in the LIFT, although on average the RIFT values tend to be lower. The values for the minimum flux for heat spread are comparable between the RIFT and the LIFT, for values which are under the recommended limit for successful RIFT tests. The correlated values for the minimum ignition heat flux were consistently higher than the experimental values in both the LIFT and RIFT, similar to Quintiere et al. [10].

The RIFT has been shown to be successful for measuring flame spread properties, however there appears to be limitations on materials which can be reliably employed. These limitations are dictated by the smaller scale such that the effects of errors on the results are more pronounced. The shape of the flux distribution profile along the sample has a sharp decay due to the directionality of the cone element, which leads to insufficient flame spread for accurate results for materials where the flux required for flame spread $\dot{q}_{s}^{\prime \prime}>7 \mathrm{~kW} / \mathrm{m}^{2}$. This suggests a maximum limit for the minimum flux for ignition $\dot{q}_{i g, \min }^{\prime \prime}$ of 18 to $19 \mathrm{~kW} / \mathrm{m}^{2}$, although this limit is not clearly defined. The material behaviour during flame spread also limits the suitability of materials that can be tested. Melteca-faced MDF tests showed that the erratic behaviour caused by the Melteca facing meant that it was more difficult to obtain good data. This finding is in line with Quintiere et al's original expectation that materials be 'well behaved'. As only wood based products were tested, the conclusions regarding the suitability of the RIFT can only be in relation to these types of materials.

\section{ACKNOWLEDGEMENTS}

The authors would like to thank Grant Dunlop and Bob Smith for their assistance in constructing the various test apparatus. We would also like to acknowledge the New Zealand Fire Service Commission for their support of the Fire Engineering programme at the University of Canterbury. 
1. Cleary T, Quintiere J. Framework for utilizing fire property tests - NISTIR 4619. International Association for Fire Safety Science. Proc. 3rd International Symposium. July 8-12, 1991, Edinburgh, Scotland, Publ. Elsevier Applied Science, New York, Editors Cox G.; Langford B. pp 647-656, 1991. doi:10.3801/IAFSS.FSS.3-647

2. ASTM E 1317-97a. Standard test method for flammability of marine surface finishes. ASTM International, West Conshohocken, PA, USA, 1997.

3. Babrauskas V. Flame fluxes in opposed flow flame spread; a review of the literature. SP report 1995:06, SP Swedish National Testing and Research Institute, Sweden, 1995.

4. ASTM E 1354. Standard test method for heat and visible smoke release rates for materials using an oxygen consumption calorimeter. ASTM International, West Conshohocken, PA, USA, 2004.

5. Goransson U. Using the cone calorimeter to predict flame spread. Nordtest project 882-90, SP Report AR1991:32, Swedish National Testing and Research Institute, Boras, Sweden, 1990.

6. Azhakesan A, Shields T, Silcock G. Ignition and opposed flow flame spread using a reduced scale attachment to the cone calorimeter. Fire Technology, Vol. 34, No. 2, pp.99-115, 1998. doi:10.1023/A:1015373301828

7. Azhakesan A, Shields T, Silcock G. Combustibility parameters for enclosure lining materials obtained during surface flame spread using reduced scale ignition and flame spread technique. Fire Technology, Vol. 34, No. 3, pp.197-226, 1998. doi:10.1023/A:1015393806371

8. Quintiere J. A simplified theory for generalizing results from a radiant panel rate of flame spread apparatus. Fire and Materials, Vol. 5, No. 2, pp. 52-60, 1981. doi:10.1002/fam.810050204

9. Quintiere J, Harkleroad M, Walton D. Measurement of flame spread properties. Combustion Science and Technology, Vol. 32, pp. 67-89, 1983. doi:10.1080/00102208308923653

10. Quintiere J, Harkleroad M. New concepts for measuring flame spread properties NBSIR 84-2943. National Institute of Standards and Technology, Gaithersburg, MD, USA, Nov 1984.

11. Merryweather, G. Comparison of Flame Spread Measurements using the ASTM E 1321 LIFT and a Reduced Scale Adaptation of the Cone Calorimeter, Masters of Engineering in Fire Engineering Thesis, University Of Canterbury, New Zealand, 2006

12. Babrauskas V. Ignition handbook. Fire Science Publishers, Fire Science and Technology, Inc, Issaquah, WA, USA, 2003.

13. Babrauskas V. Ignition of Wood: A review of the state of the art. Proc. 9th Int'l Interflam Conference, September 17-19, 2001, Edinburgh, Scotland. Interscience Communications Ltd., London, England, pp. 7188,2001 .

14. Dietenberger M. Ignitability analysis using the cone calorimeter and LIFT apparatus. Proc. Int'l Conference on Fire Safety: July 22-26, 1996, Columbus, OH. Vol. 22. pp. 189-197, 1996.

15. ASTM E 1317-97a. Standard test method for flammability of marine surface finishes. American Society of Testing and Materials, ASTM International, West Conshohocken, PA, USA, 1997.

16. Grand A F, Mehrafza M. Evaluation of the effectiveness of fire resistant durable agents on residential siding using an ICAL based testing protocol. Proc. Fire and Materials 2001, $7^{\text {th }}$ Int'l Conference. Interscience Communications Ltd. Jan 22-24, 2001, San Antonio, Texas, USA. pp. 241-248, 2001. 
17. ASTM E 1623 Standard test method for determination of fire and thermal parameters of materials, products, and systems using an intermediate scale calorimeter. ASTM International, West Conshohocken, PA, USA, 2004.

18. Pauner M. Nordic round robin and investigation on IMO Resolution A. 653 (16) TR 529. Nordtest, Finland, April 2003.

19. Ngu M. Ignition of New Zealand timber. Masters of Engineering in Fire Engineering thesis, University of Canterbury, Christchurch, New Zealand, 2002.

20. Nisted T, Flame spread experiments in bench scale: Project 5 of the EUREFIC fire research programme. UDC 614.841.41: 691.1: 53.0896, Dantest Fire Technology, Denmark, 1991.

21. Babrauskas V, Wetterlund I. Comparative data from LIFT and cone calorimeter tests on 6 products, including flame flux measurements. SP report 1999:14, Swedish National Testing and Research Institute, Boras, Sweden, 1999.

22. Pease T. A study of surface flame spread using a modified cone calorimeter. Undergraduate final year project. Department of Chemical Engineering, University of Newcastle, Australia, 2001.

23. Huynh C K. Flame spread measurements of New Zealand timber using a modified cone calorimeter. Masters of Engineering in Fire Engineering thesis, University of Canterbury, Christchurch, New Zealand, 2003.

24. Merryweather G, Spearpoint M. Ignition of New Zealand wood products in the LIFT, RIFT and ISO 5657 apparatus using the ASTM E 1321-97 protocol. Journal of Fire Sciences, Vol. 26, No. 1, pp. 63-88, 2008. doi:10.1177/0734904107085381

25. Younquist J. Wood based products and panel products. Wood handbook - Wood as an engineering material. Gen. Tech. Rep. FPL-GTR-113. Forest Products Laboratory, Madison, WI, 1999.

26. Jianmin Q. Prediction of flame spread test results using the test data from the cone calorimeter. SP Report 1990:38, Swedish National Testing and Research Institute, Boras, Sweden, 1990.

27. Fowell A. Inter-laboratory test program on ASTM E 1321: Standard test method for measuring material ignition and flame spread properties (2nd ed.), ASTM International, West Conshohocken, PA, USA, 1994. 